University of Wollongong

Research Online

Faculty of Engineering and Information

Faculty of Engineering and Information

Sciences - Papers: Part A

Sciences

$1-1-2016$

Performance improvement of rail track substructure using artificial inclusions - experimental and numerical studies

Buddhima Indraratna

University of Wollongong, indra@uow.edu.au

Sanjay Nimbalkar

University of Wollongong, sanjayn@uow.edu.au

Ngoc Trung Ngo

University of Wollongong, trung@uow.edu.au

Tim Neville

Australian Rail Track Corporation Ltd

Follow this and additional works at: https://ro.uow.edu.au/eispapers

Part of the Engineering Commons, and the Science and Technology Studies Commons

Research Online is the open access institutional repository for the University of Wollongong. For further information contact the UOW Library: research-pubs@uow.edu.au 


\title{
Performance improvement of rail track substructure using artificial inclusions - experimental and numerical studies
}

\begin{abstract}
Large and frequent loads from heavy freight and passenger trains often lead to the progressive track deterioration. The excessive deformation and degradation of ballast and unacceptable differential settlement of track and/or pumping of underlying soft subgrade soils necessitates frequent and costly track maintenance. However, artificial inclusions such as geogrids and shockmats can mitigate ballast degradation and improve track performance. A quantitative assessment of the influence of breakage, fouling, and the effects of artificial inclusions on the shear behaviour of ballast can be performed either experimentally or numerically. Numerical modelling can simulate these aspects subject to various types of loading and boundary conditions for a range of material properties so in this study, the stress-strain and degradation response of ballast was analysed through discrete element (DEM) and finite element (FEM) methods. In DEM, irregularly shaped ballast aggregates were simulated by clumping together spheres in appropriate sizes and positions. In FEM, a composite multi-layer track system was simulated and an elasto-plastic model with a non-associative flow rule was used to capture ballast degradation. These DEM and FEM simulations showed a good agreement with large-scale laboratory tests. This paper outlines the advantages of the proposed DEM and FEM models in terms of capturing the correct stressstrain and degradation response of ballast with particular emphasis on particle breakage and fouling, as well as applications of geosynthetic grids and shockmats.
\end{abstract}

\section{Keywords}

artificial, performance, inclusions, substructure, track, studies, experimental, numerical, rail, improvement

Disciplines

Engineering | Science and Technology Studies

\section{Publication Details}

Indraratna, B., Nimbalkar, S. Shrawan., Ngo, N. Trung. \& Neville, T. (2016). Performance improvement of rail track substructure using artificial inclusions - experimental and numerical studies. Transportation Geotechnics, 8 69-85. 


\section{Accepted Manuscript}

Performance Improvement of Rail Track Substructure using Artificial Inclusions - Experimental and Numerical Studies

Buddhima Indraratna, Sanjay Nimbalkar, Ngoc Trung Ngo, Tim Neville

PII:

$$
\text { S2214-3912(16)30004-6 }
$$

DOI: http://dx.doi.org/10.1016/j.trgeo.2016.04.001

Reference: TRGEO 77

To appear in:

Received Date: $\quad 25$ June 2015

Revised Date: $\quad 30$ March 2016

Accepted Date: $\quad 4$ April 2016

Please cite this article as: B. Indraratna, S. Nimbalkar, N. Trung Ngo, T. Neville, Performance Improvement of Rail Track Substructure using Artificial Inclusions - Experimental and Numerical Studies, (2016), doi: http://dx.doi.org/ 10.1016/j.trgeo.2016.04.001

This is a PDF file of an unedited manuscript that has been accepted for publication. As a service to our customers we are providing this early version of the manuscript. The manuscript will undergo copyediting, typesetting, and review of the resulting proof before it is published in its final form. Please note that during the production process errors may be discovered which could affect the content, and all legal disclaimers that apply to the journal pertain. 


\title{
Performance Improvement of Rail Track Substructure using Artificial Inclusions - Experimental and Numerical Studies
}

\author{
Buddhima Indraratna \\ BSc (Hons., Lond.), MSc (Lond.), DIC, PhD (Alberta), FIEAust., FASCE, FGS \\ Professor of Civil Engineering and Research Director, \\ Centre for Geomechanics and Railway Engineering, \\ University of Wollongong, Wollongong City, NSW 2522, Australia \\ e-mail:indra@uow.edu.au \\ Sanjay Nimbalkar \\ BEng, MTech (IIT Bombay), PhD (IIT Bombay) \\ Research Fellow, Centre for Geomechanics and Railway Engineering, \\ University of Wollongong, Wollongong City, NSW 2522, Australia \\ e-mail: sanjayn@uow.edu.au \\ Ngoc Trung Ngo \\ BEng, MEng (Wollongong), $\mathrm{PhD}$ (Wollongong) \\ Lecturer, School of Civil, Mining and Environmental Engineering, \\ University of Wollongong, Wollongong City, NSW 2522, Australia \\ e-mail: trung@uow.edu.au

\section{Tim Neville \\ BEng (Hons.)} \\ Senior Geotechnical Engineer, Australian Rail Track Corporation Ltd., \\ Broadmeadow, NSW 2292, Australia \\ e-mail: tneville@artc.com.au
}

Date of Submission of Revised Manuscript: 29 March 2016

Words in main text: 4630; Tables: 2; Figures: 12

Submitted to: Transportation Geotechnics: "Geosynthetics in Transportation Infrastructure" Special Issue

Author for correspondence: Prof. B. Indraratna, Professor of Civil Engineering and Research Director, Faculty of Engineering, University of Wollongong, Wollongong, NSW 2522 Australia.Ph: +61 24221 3046; Fax: +61 242213238 


\section{Performance Improvement of Rail Track Substructure using Artificial Inclusions - Experimental and Numerical Studies}

\section{Buddhima Indraratna ${ }^{1}$, Sanjay Nimbalkar ${ }^{2},{\text { Ngoc Trung } \mathrm{Ngo}^{3} \text { and Tim Neville }}^{4}$}

ABSTRACT: Large and frequent loads from heavy freight and passenger trains often lead to the progressive track deterioration. The excessive deformation and degradation of ballast and unacceptable differential settlement of track and/or pumping of underlying soft subgrade soils necessitates frequent and costly track maintenance. However, artificial inclusions such as geogrids and shockmats can mitigate ballast degradation and improve track performance. A quantitative assessment of the influence of breakage, fouling, and the effects of artificial inclusions on the shear behaviour of ballast can be performed either experimentally or numerically. Numerical modelling can simulate these aspects subject to various types of loading and boundary conditions for a range of material properties so in this study, the stressstrain and degradation response of ballast was analysed through discrete element (DEM) and finite element (FEM) methods. In DEM, irregularly shaped ballast aggregates were simulated by clumping together spheres in appropriate sizes and positions. In FEM, a composite multilayer track system was simulated and an elasto-plastic model with a non-associative flow rule was used to capture ballast degradation. These DEM and FEM simulations showed a good agreement with large-scale laboratory tests. This paper outlines the advantages of the proposed DEM and FEM models in terms of capturing the correct stress-strain and degradation response of ballast with particular emphasis on particle breakage and fouling, as well as applications of geosynthetic grids and shockmats.

\section{KEYWORDS: Ballast, fouling, numerical model, geosynthetics, shockmats, geogrids}

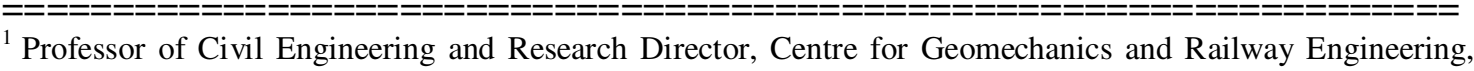
University of Wollongong, Wollongong City, NSW 2522, Australia. e-mail: indra@uow.edu.au.

${ }^{2}$ Research Fellow, Centre for Geomechanics and Railway Engineering, University of Wollongong, Wollongong City, NSW 2522, Australia. e-mail: sanjayn@uow.edu.au

${ }^{3}$ Lecturer, School of Civil, Mining and Environmental Engineering, University of Wollongong, Wollongong City, NSW 2522, Australia. e-mail: trung@uow.edu.au

${ }^{4}$ Senior Geotechnical Engineer, Australian Rail Track Corporation Ltd., Broadmeadow, NSW 2292, Australia. e-mail: tneville@artc.com.au
} 


\section{INTRODUCTION}

Ballasted railways form an integral part of the transportation infrastructure and play a significant role in sustainable economic growth. In Australia, most of the interstate freight railway corridors fall in the coastal belt and face problems of poor subgrade (soft coastal deposits) or hilly (or undulating) terrain that often restrict train speeds. Owing to the recent rapid growth in the volume and tonnage of rail traffic, many of the existing railroads are fast becoming structurally inadequate and are in need costly maintenance, most of which would be spent on the substructure. The lack of attention given to appropriately designed substructure is often associated with the complex behaviour of the heterogenous materials involved (ballast, subballast, and subgrade), and the problem of too many design variables [1]. Rail tracks should be designed to withstand large cyclic train loadings while protecting the subgrade soils against progressive shear failure and excessive plastic deformation [2].

The ballast layer contributes more to track settlement than the subballast and subgrade layers due to its complex behaviour under train loading. For instance, the progressive accumulation of coal and crushed rock fines (due to particle breakage) in the voids fouls the ballast and adversely affects the performance of track [3,4], and discrete wheel/rail irregularities such as wheel flats, rail corrugations, dipped rails, defective rail welds, insulated joints and rail expansion gaps can induce substantial impact loads [5,6] that accelerate degradation [7]. Although geosynthetics and shockmats can help to mitigate the detrimental effects of fouling and particle breakage [7-14], our existing knowledge of the behaviour of ballastgeosynthetics or the ballast-mat interface through numerical studies is still limited.

The discrete element method (DEM) that was introduced by Cundall and Strack [15] has been widely used to simulate granular materials [16-19], but the application of DEM to study the behaviour of fouled ballast and analyse its interface mechanism with the reinforcing geogrid 
is limited. Several multi-layer track models have been developed to analyse the inherent stresses and deformations in all the major components of track and subgrade, i.e., the rails, fasteners, sleepers, ballast, sub-ballast, and subgrade [20-22], but they all assume an elastic behaviour for the track layers, including the ballast. Compared to three dimensional track components simulated in earlier elastic models [20-22], the numerical models described in this study reproduce simple (two dimensional) geometry. In the field, based on two extensively monitored case studies (towns of Bulli and Singleton in New South Wales), the longitudinal strains (in the direction of train travel) were measured to be very small compared to the transverse direction justify the assumption of two-dimensional plain strain simulated in the numerical model $[23,24]$. Pronounced three-dimensional behavior is observed when approaching turnouts, curves and track transition zones [25,26].

The elastoplastic continuum modelling approach adopted in this study can capture the progressive development of irreversible plastic deformations, particle breakage, and ballast fouling under influence of repetitive loads as evident from laboratory data. These important plasticity mechanisms are primarily responsible for ballast degradation often demanding frequent track maintenance, but have been ignored in elastic models [27-31]. An elastoplastic continuum modelling approach is necessary to simulate the overall plastic deformation and degradation response of ballast at a large number of loading cycles. In addition, these elastic models do not consider the actual cyclic nature of wheel loading. In this paper, the salient aspects of ballast deformation are discussed through the use of the two-dimensional (2D) DEM and the finite element method (FEM). Here, the ballast layer was simulated as a single unit in DEM, while an FEM analysis was carried out on an integrated track model. Advanced elasto-plastic constitutive models were implemented in FEM. Subsequently, the interaction between track components was incorporated by defining suitable boundary 
conditions and load transfer mechanisms, and then multilayered track models were simulated to capture the behaviour observed through large-scale laboratory data.

\section{CURRENT STATE OF THE ART}

\subsection{Assessment of Ballast Breakage}

Ballast usually consists of medium to coarse sized sharp angular aggregates that progressively break under heavy cyclic and impact loads leading to the attrition of asperities. Indraratna et al. [32] introduced a Ballast Breakage Index $(B B I)$ to quantify the extent of degradation based on the particle size distribution (PSD) curves; the $B B I$ is calculated based on changes in the fraction passing a range of sieves. This increase in the extent of particle breakage causes the $P S D$ curve on a conventional $P S D$ plot to shift further towards the region of smaller size particles, so by referring to the linear particle size axis, the $B B I$ can be determined, i.e. $B B I=A /(A+B)$, where $A$ is the shift in the $P S D$ curve during test and $B$ is the potential breakage or area between the arbitrary boundary of maximum breakage and the final PSD. Using this method, ballast breakage is assessed under cyclic and impact loading, as reported in this paper.

\subsection{Assessment of Ballast Fouling}

Ballast fouling is one of the main areas of rail track maintenance, and fouling material is usually defined as material passing through a $9.5 \mathrm{~mm}$ sieve [1]. Several potential sources of ballast fouling can be attributed to sleeper wear, particle breakage, infiltration from underlying subballast and subgrade layers (e.g. clay fouling), and spillage as wagons are being transported (e.g. coal fouling) [33], along with environmental sources such as dust, wind-blown sand, etc. In Australia, coal and ballast breakage are major sources of ballast fouling and contribute from 70-95\% and 5-30\% of ballast fouling respectively [3]. 
In practice, several fouling indices were used to measure fouling. Selig and Waters [1] defined the fouling index as a summation of the percentage (by weight) of a sample of fouled ballast passing through a $4.75 \mathrm{~mm}$ sieve and a $0.075 \mathrm{~mm}$ sieve. Jeffs and Martin [34] assessed ballast fouling for Queensland Railways using the D-bar $(\bar{D})$ test, a geometrical mean particle size based on the particle size distribution of a sample of fouled ballast. Recently, Indraratna et al. [35] defined a new parameter, the Void Contaminant Index (VCI), which is expressed as:

$$
V C I=\frac{1+e_{f}}{e_{b}} \times \frac{G_{s . b}}{G_{s . f}} \times \frac{M_{f}}{M_{b}} \times 100
$$

where $e_{f}$ and $e_{b}$ are the void ratios of the fouling material and clean ballast, $G_{s . f}$ and $G_{s . b}$ are the specific gravities of the fouling material and the clean ballast, and $M_{f}$ and $M_{b}$ are the dry mass of the fouling material and clean ballast. Defining the volume fractions $F_{b}=V_{b} / V_{T}, F_{c f}$ $=V_{c f} / V_{T}$ for ballast and coal fines respectively means that Eq. (1) can be rewritten as [3]:

$$
V C I=\frac{v_{c f} F_{c f}}{1-F_{b}} \times 100
$$

where $e_{c f}$ and $v_{c f}=1+e_{c f}$ are the void ratio and specific volume of fouling (clay, coal etc.). $V_{b f}$ and $V_{c f}$ are volumes of ballast fines and of fouling material, respectively. The ballast fines are defined as aggregates smaller than $9.5 \mathrm{~mm}$ accumulated in the voids as a result of progressive particle breakage during loading [36]. $V_{b}$ is the volume of ballast and $V_{T}$ is the total volume of fouled ballast (Fig. 1). In general, ballast specifications require a uniform gradation (i.e. the coefficient of uniformity where $C_{u}=1.5-3.0$ ) to fulfill its requirements as a free draining material, so the there is no significant change in the void ratio of clean ballast $\left(e_{b}\right)$. However, there is a significant variation in the void ratio, specific gravity, and gradation of the fouling materials and the VCI can capture this more effectively than other indices. Fig. 
2 shows the correlation between the fouling indices and VCI for various percentages of coal fouling. In this paper, VCI was used to measure the amount of coal fouling.

\subsection{Assessment of Impact Loads}

Track degradation is usually driven by the wheel/rail impact loads that are referred to as the static load and peak loads. Two distinct types of peaks, viz. an instantaneous sharp peak $\left(P_{1}\right)$, and a gradual peak of smaller magnitude with much longer duration $\left(P_{2}\right)$ are generally observed during impact loading [5, 7].

$P_{2}$ forces are more important because they last longer and are the primary cause of track substructure degradation. Jenkins et al. [5] proposed a theoretical formula to calculate the $P_{2}$ forces, given as:

$$
P_{2}=P_{0}+2 \alpha V \sqrt{\frac{M_{u}}{M_{u}+M_{t}}} \cdot\left[1-\frac{C_{t} \pi}{4 \sqrt{K_{t}\left(M_{u}+M_{t}\right)}}\right] \cdot \sqrt{K_{t} M_{u}}
$$

where $P_{0}$ is static single wheel load $(\mathrm{kN}), M_{u}$ is unsprung mass per wheel $(\mathrm{kg}), 2 \alpha$ is total joint angle $(\mathrm{rad})$, and $V$ is the train speed $(\mathrm{m} / \mathrm{s}) . K_{t}\left[=2 K_{t d} \beta\right]$ is the equivalent track stiffness $(\mathrm{MN} / \mathrm{m}), C_{t}\left[=1.5 C_{t d} \beta\right]$ is the equivalent track damping $(\mathrm{kNs} / \mathrm{m}), M_{t}\left[=1.5 M_{t d} \beta\right]$ is the equivalent track mass $(\mathrm{kg}), \beta\left[=\left(K_{t d} /(4 E I)\right]^{-0.25}\right]$ is an effective track length, $K_{t d}$ is the Ballast Stiffness per metre $(\mathrm{MN} / \mathrm{m} / \mathrm{m}), C_{t d}$ is the Ballast Damping per metre $(\mathrm{kNs} / \mathrm{m} / \mathrm{m})$, and $M_{t d}$ is the mass of the rail + sleeper per metre $(\mathrm{kg} / \mathrm{m})$. In order to cover the current state-of-the-art knowledge of rail track geomechanics, important concepts/topics related to finite element and discrete element modeling approaches are described herewith. Both geogrids and shock mats have been used in tandem in track segments hence they do have an interaction in a practical sense. Moreover, shock mats are now manufactured from synthetic (polymeric) material, and not just from natural rubber, hence these shock mats can be classified as geosynthetics in a strict sense. In view of these aspects, Sections 2.4 and 2.5 have interplay both in terms of 
collateral mechanical influence in track, as well as description under common terminology. The numerical aspects of ballast degradation and its stabilisation using geosynthetics and shockmats are described in detail in the subsequent sections of this paper.

\subsection{Discrete Element Modelling}

The DEM can accurately model the discrete nature of ballast aggregates by providing an insight into micromechanical factors such as particle shape, the contact force distributions developed between particles, and the evolution of fabric anisotropy that are difficult to measure in the laboratory. These aspects, including the computational procedure, are discussed in the following section.

\subsubsection{Computational procedure}

The DEM method tracks the motion of individual particles and updates any contact forces between neighbouring particles using a constitutive contact law. The contact force vector $F_{i}$ can be decomposed into the normal component $\left(F_{i}^{n}\right)$ and shear component $\left(F_{i}^{s}\right)$ as given by:

$$
F_{i}=F_{i}^{n}+F_{i}^{s}
$$

The normal contact force vector is calculated by the overlap between two contacting particles, as given by:

$$
F_{i}^{n}=k^{n} U^{n} n_{i}
$$

where $k^{n}$ is the normal stiffness at the contact, $U^{n}$ is the normal displacement (i.e. overlap), and $n_{i}$ is the unit normal vector of the contact plane. The shear contact force is determined in an increment with shear displacement, as determined by:

$$
\Delta F_{i}^{s}=-k^{s} \Delta U_{i}^{s}
$$

where $\Delta F_{i}^{s}$ is the increment in shear force, $k^{s}$ is the shear stiffness at the contact, and $\Delta U_{i}^{s}$ is the increment in shear displacement, determined as: 


$$
\Delta U_{i}^{s}=V_{i}^{s} \Delta t
$$

where $V_{i}^{s}$ is the shear component of the contact velocity and $\Delta t$ is the critical time-step. Finally, the new shear contact force is computed by accumulating the current shear force $\left\{F_{i}^{s}\right\}^{[\text {current }]}$ at the contact with the increment in shear force, as given by:

$$
F_{i}^{s}=\left\{F_{i}^{s}\right\}^{[\text {current }]}+\Delta F_{i}^{s}
$$

The entities representing particles in DEM are spherical balls, but their excessive rolling and inability to interlock [37] means that granular particles that are irregular and angular in nature cannot be modelled. In this study, irregular grains of ballast were simulated via "clump logic", i.e., a method of creating irregular particles by connecting and overlapping a number spheres of different sizes and coordinates [38]. A library of six different ballast shapes and sizes were simulated in DEM for the current analysis, as shown in Fig. 3. Because a clump has a rigid body, its motion can be described in terms of the translational motion of a point in the clump and the rotational motion of the entire clump. The equation for translational motion can be expressed in vector form:

$F_{i}=m\left(\ddot{x}_{i}-g_{i}\right)$

where $F_{i}$ is the resultant force, the sum of all externally applied forces acting on the clump, and $g_{i}$ is the body force acceleration vector arising from gravity loading. The equation for rotational motion can be written in the matrix form and described by [38]:

$\{M\}-\{W\}=[I]\{\alpha\}$

where,

$$
[M]=\left\{\begin{array}{l}
M_{1} \\
M_{2} \\
M_{3}
\end{array}\right\} \quad[I]=\left[\begin{array}{lrr}
I_{11} & -I_{12} & -I_{13} \\
-I_{21} & I_{22} & -I_{23} \\
-I_{31} & -I_{32} & I_{33}
\end{array}\right] \quad[\alpha]=\left\{\begin{array}{l}
\alpha_{1} \\
\alpha_{2} \\
\alpha_{3}
\end{array}\right\}=\left\{\begin{array}{l}
\dot{\omega}_{1} \\
\dot{\omega}_{2} \\
\dot{\omega}_{3}
\end{array}\right\}
$$




$$
[W]=\left\{\begin{array}{l}
\omega_{2} \omega_{3}\left(I_{33}-I_{22}\right)+\omega_{3} \omega_{3} I_{23}-\omega_{2} \omega_{2} I_{32}-\omega_{1} \omega_{2} I_{31}+\omega_{1} \omega_{3} I_{21} \\
\omega_{3} \omega_{1}\left(I_{11}-I_{33}\right)+\omega_{1} \omega_{1} I_{31}-\omega_{3} \omega_{3} I_{13}-\omega_{2} \omega_{3} I_{12}+\omega_{2} \omega_{1} I_{32} \\
\omega_{1} \omega_{2}\left(I_{22}-I_{11}\right)+\omega_{2} \omega_{2} I_{12}-\omega_{1} \omega_{1} I_{21}-\omega_{3} \omega_{1} I_{23}+\omega_{3} \omega_{2} I_{13}
\end{array}\right\}
$$

and where $[M]$ is the resultant moment about the centre of mass, and $\omega_{i}$ and $\dot{\omega}_{i}$ are the angular velocity and angular acceleration about the principal axes, respectively.

\subsubsection{Discrete element modelling of fouled ballast subjected to direct shear testing}

A large scale shear box $300 \mathrm{~mm}$ long $\times 300 \mathrm{~mm}$ wide $\times 200 \mathrm{~mm}$ high was simulated with rigid walls, as shown in Fig. 4. A total of 8281 ballast particles were generated at random orientations to simulate actual ballast gradation, as used in the laboratory. Six particle shapes were selected to approximately represent the actual shape and angularity of aggregates, where each particle has a different grain size. A predetermined quantity of each grain size was then placed into the DEM model to represent actual ballast gradation carried out in the laboratory. The void ratio of the assembly representing the initial condition of the test specimen was controlled at 0.82 (i.e. porosity of $45 \%$ ). The micromechanical parameters (normal and shear stiffness of the ballast particles, friction coefficient) used in the current DEM analysis were selected by conducting a calibration of a clump assembly subjected to large-scale direct shear testing with respect to the experimental data reported by Indraratna et al. [8]. The VCI that was defined earlier in Section 2.2 was used to quantify ballast fouling. Size of fine particles carried out in laboratory varied from $0.1-10 \mathrm{~mm}$, where the median value of the particle size distribution $\mathrm{d}_{50}=1.5 \mathrm{~mm}$ [8]. Fouled ballast $(V C I=40 \%)$ was simulated in DEM by adding a predetermined number of $1.5 \mathrm{~mm}$ radius spheres (e.g. 145,665 particles) into the voids of fresh ballast, which was similar to the median value of the particle size distribution curve of coal fines, i.e. $\mathrm{d}_{50}$ as evaluated in the laboratory (Fig. 4b). The DEM properties for coal were 
determined based on the calibration using direct shear testing of coal fines. DEM simulations were then carried out to model fresh ballast and coal fouled ballast $(V C I=40 \%)$ that was subjected to normal stresses that varied from $15 \mathrm{kPa}$ to $75 \mathrm{kPa}$. Figure 5 presents comparisons of the shear stress-strain response and volumetric change obtained from DEM and those measured in the laboratory by Indraratna et al. [8]. It is seen that the shear stress versus shear strain curves obtained from the DEM simulation reasonably agree with those measured experimentally. In every simulation the ballast exhibited compression behaviour at the beginning of the test, followed by significant dilation. Volumetric dilation occurred in every simulation such that the higher the normal stress $\left(\sigma_{n}\right)$, the greater the peak stress and the smaller the dilation, as expected. Unlike fresh ballast $(V C I=0 \%)$, the fouled ballast $(V C I=$ $40 \%$ ) exhibited reduced shear strength at a given normal stress because the fine particles would decrease the inter-particle friction by coating the surfaces of rough aggregates, and thus reduce the shear strength. Coal fines also act as a lubricant that accelerates particle displacement and rearrangement, which in turn increases dilation and decreases the stability of the ballast layer. It is worth mentioning that there was some disparity in volumetric strains between the numerical predictions and experimental data, probably associated with particle angularity and the particle degradation that was not considered accurately in the current DEM analysis. Lackenby et al. [39] indicated that particle breakage could increase ballast compression, while the laboratory results indicated a sudden decrease in shear stress at 5-7\% shear strain, before picking up the load again, which further supports the initiation of particle degradation at this level of shear strain (Fig. 5). Despite this disparity, the DEM model proposed in this study successfully captured the shear stress-strain and volumetric dilation of fresh and fouled ballast under any given normal stress.

\subsubsection{Discrete element modelling of fouled ballast subjected to cyclic loading}


DEM simulations were also carried out to study the load-deformation behaviour of fresh and coal-fouled ballast subjected to cyclic loading. The experimental data presented by Indraratna et al. [40] were used to calibrate and compare with the DEM model; and the sizes and shapes of actual ballast aggregates (Fig. 6a) introduced by Indraratna et al. [41] were adopted where clusters of bonded circular spheres were used to model irregular shaped grains of ballast. Fig. 6 represents a cross-section of unique process simulation dynamic triaxial apparatus designed and built at the University of Wollongong. The configuration of experiment carried out by Indraratna et al. [40] including a unique large-scale cubical triaxial apparatus with a dynamic actuator (specimen size: $800 \mathrm{~mm} \times 600 \mathrm{~mm} \times 600 \mathrm{~mm}$ ). The four vertical walls of the apparatus were connected to a system of ball bearings and hinges which allowed them to displace laterally with minimum resistance. A $150 \mathrm{~mm}$-thick capping and subgrade layer, made from coarse sand and gravel mixture, was placed at the bottom of the apparatus and compacted to a bulk unit weight of $18 \mathrm{kN} / \mathrm{m}^{3}$. The ballast was then placed above the capping layer (i.e. subballast) and compacted in every $50 \mathrm{~mm}$-thick sublayer to a field unit weight of approximately $15.5 \mathrm{kN} / \mathrm{m}^{3}$, until the final height of the ballast layer attained $300 \mathrm{~mm}$. Cyclic loads were applied where the maximum induced cyclic stress of $\sigma_{\max }=420 \mathrm{kPa}$ (frequency of $f=15 \mathrm{~Hz}$ ) was adopted in this study. All tests were conducted to 500,000 load cycles.

The degradation of bonds within a cluster was considered to represent ballast breakage, while coal fines were simulated in DEM by placing a predetermined amount of $1.5 \mathrm{~mm}$ diameter spheres into the voids to represent a specific VCI (i.e. 1095, 2190, 4380, and 7665 spheres to represent $V C I=10 \%, 20 \%, 40 \%$, and $70 \%$, respectively). The DEM boundary conditions were identical to those conducted in the laboratory tests, and are shown in Fig. 6b. The authors developed sub-routines to apply a stress-controlled cyclic simulation by adjusting the position and velocity of the vertical and top walls using a numerical servo-control mechanism [38]. Cyclic tests for fresh and fouled ballast where $V C I=10 \%, 20 \%, 40 \%$, and $70 \%$ were 
carried out to 4000 load cycles where most of the plastic deformation and degradation took place as measured in the laboratory. The lateral displacement and vertical settlement of the ballast assembly was determined by monitoring the movement of vertical and horizontal walls. It is noted that the DEM model in Fig. 4 was 3-dimensional simulating large-scale direct shear tests, where the model in Fig. 6 was 2-dimensional (i.e. plane strain) simulating cyclic loading. A 2-dimensional DEM analysis was considered for a straight track where the longitudinal displacement of ballast (i.e. along the direction of train passage) could be considered insignificant compared to the transverse direction (parallel to sleepers).

Figure 7 shows a comparison between the lateral displacement, settlement, and number of broken bonds with the load cycles obtained from the DEM and those measured experimentally, and also indicates that the DEM simulation successfully captured the loaddeformation response of fresh and fouled ballast subjected to cyclic loading. Fig. 7a shows accumulated lateral displacement of the ballast assembly under cyclic load. The results obtained from the DEM simulation confirmed that the level of fouling significantly affected ballast deformation where an increase in the VCI resulted in an increased lateral displacement (Fig. 7a) and increased settlement (Fig. 7b). Fig. 7c also shows that the accumulated number of broken bonds decreased as the VCI increased; this finding agrees with the data measured in the laboratory where an increase in the level of coal fouling exhibited a reduced ballast breakage. Ballast aggregates experienced significant degradation resulting in changes of the grain size distribution as measured in the laboratory (Lackenby et al. [39]). The current DEM analysis quantified these changes in grain size distribution by capturing the number of broken bonds which is a quantitative representation of particle breakage observed in the laboratory (Fig. 7c). This observation is further justified by Fig. 8 which presents the contact force distributions of fresh and fouled ballast $(V C I=70 \%)$. When fines accumulated in the voids the load was transmitted through the large aggregate skeleton and across the fine particles. This 
resulted in a more uniform contact force distribution in the fouled ballast, a result that would reduce ballast breakage by diminishing the intensity of stress concentrated in the fouled ballast matrix. The current DEM models have obvious limitations due to excessive computational time required, where a large number of cycles cannot be simulated.

\subsection{Finite Element Modelling}

Finite element modelling of rail track structure is essentially a 2D problem because in reality, the longitudinal deformation of a long straight section of track section (i.e., perpendicular to the sleepers) are generally very small, thus ensuring plane-strain conditions $[11-14,35]$. In this paper a higher order constitutive model and interface elements were used to capture the real behaviour of the track. Whilst DEM is better for modelling the aggregate-geogrid interlock mechanism, FEM was chosen to simulate the overall plastic deformation and degradation response of ballast at the large number of loading cycles appropriate for rail track traffic. FEM can simulate up to 10000 loading cycles [42] whereas DEM cannot handle more than a few thousand cycles (PFC2D or PFC3D), as described in the earlier Section. The details of finite element modelling are elucidated in the following sections.

\subsubsection{Angles of dilatancy and friction of ballast}

The stress-dilatancy theory $[43,44]$ can be modified to incorporate particle breakage under triaxial monotonic loading:

$$
\frac{\sigma_{1}^{\prime}}{\sigma_{3}^{\prime}}=\left(1-\frac{d \varepsilon_{v}^{p}}{d \varepsilon_{1}^{p}}\right) \tan ^{2}\left(45+\frac{\phi_{f}^{\prime}}{2}\right)+\frac{d E_{B}}{\sigma_{3}^{\prime} d \varepsilon_{1}^{p}}\left(1+\sin \phi_{f}^{\prime}\right)
$$

where $\phi_{f}^{\prime}$ is the effective friction angle excluding the effect of dilation and particle breakage $\left(\phi_{f}^{\prime}=44^{0}\right)$, and $d E_{B}$ is the incremental energy consumption by particle breakage per unit volume. By incorporating the $B B I$ defined in Section $2.1, d E_{B}$ can be expressed as: 


$$
\left(\frac{d E_{B}}{d \varepsilon_{1}^{p}}\right)=\kappa\left[\left(\frac{d B B I}{d \varepsilon_{1}^{p}}\right)\right]
$$

where $\kappa$ is the constant of proportionality $(\kappa=175.8)$. The non-associated plastic flow rule incorporating the rate of particle breakage during shearing is represented by:

$$
d \varepsilon_{v}^{p}=\left[1-\left(\frac{\sigma_{1}^{\prime}}{\sigma_{3}^{\prime}}\right) \tan ^{2}\left(45-\frac{\phi_{f}^{\prime}}{2}\right)+\kappa\left(\frac{d B B I}{\sigma_{3}^{\prime} d \varepsilon_{1}^{p}}\right)\left(1-\sin \phi_{f}^{\prime}\right)\right] d \varepsilon_{1}^{p}
$$

The mobilised dilatancy angle $\psi_{m}$ during loading/reloading phase is expressed as:

$$
\sin \psi_{m}=\frac{d \varepsilon_{1}^{p}+x d \varepsilon_{3}^{p}}{d \varepsilon_{1}^{p}-x d \varepsilon_{3}^{p}}=\frac{d \varepsilon_{v}^{p} / d \varepsilon_{1}^{p}}{2-d \varepsilon_{v}^{p} / d \varepsilon_{1}^{p}}
$$

where $x$ is a constant ( $x=1$ for plane strain, and $x=2$ for axisymmetrical). By incorporating the effect of particle breakage into the equation (16), $\psi_{m}$ can be expressed as:

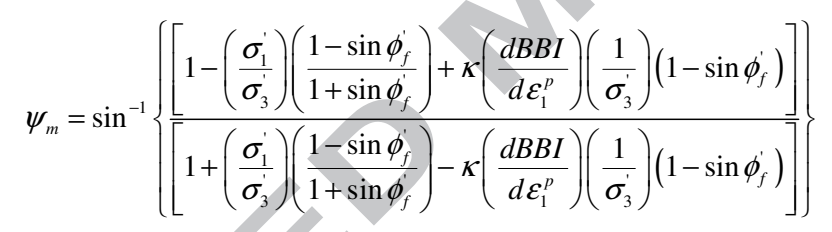

The mobilised effective friction angle $\phi_{m}{ }^{\prime}$ during the loading/reloading phase is expressed in terms of the effective major and minor principal stresses according to the Mohr-Coulomb failure criterion:

$$
\phi_{m}^{\prime}=\sin ^{-1}\left\{\frac{\sigma_{1}^{\prime}-\sigma_{3}^{\prime}}{\sigma_{1}^{\prime}+\sigma_{3}^{\prime}}\right\}
$$

Table 2 shows the values of the angles of dilatancy and friction for ballast used in the finite element (FE) analysis. In the following sections, the results of 2D axisymmetric dynamic FE analyses implemented into PLAXIS (PLAXIS 2D Version 8.6) are discussed.

\subsubsection{Finite element modelling of ballast degradation induced by cyclic loading}


The deformation of ballast is characterised by three phases [45]; the first phase is immediate deformation under the first loading cycle, the second phase is an unstable zone where rapid deformation attributed to the reorientation and rearrangement of particles occurs along with significant breakage, and the third phase is often called 'stable shakedown' where the rate of increase of deformation is insignificant. Thus, ballast deformation during cyclic loading can be determined as [45]:

$$
S_{v}=S_{v 1}\left(1+a \ln N+0.5 b \ln N^{2}\right)
$$

where the first term refers to deformation due to the first cycle, the second term refers to a unstable zone where $\mathrm{N}<10^{4}$ cycles, and the third term refers to a stable zone where $\mathrm{N}>10^{4}$ cycles. Equation (19) is differentiated with respect to the loading cycle $(N)$ and incremental axial strain is given as [45]:

$$
\frac{d \varepsilon_{1}^{p}}{d N}=\varepsilon_{11}^{p}\left(\frac{a^{\prime}}{N}+\frac{b^{\prime}}{N}\right)
$$

where $\varepsilon_{11}^{p}$ represents the vertical plastic strain after the first loading cycle, and $a^{\prime}$ and $b^{\prime}$ are two empirical constants. For axi-symmetric $\left(\sigma_{2}^{\prime}=\sigma_{3}^{\prime} ; d \varepsilon_{2}^{p}=d \varepsilon_{3}^{p}\right)$ and plane strain $\left(d \varepsilon_{2}^{p}=0\right)$ testing conditions, the incremental volumetric strain under cyclic loading is expressed as [45]:

$$
\frac{d \varepsilon_{v}^{p}}{d N}=\left[\varepsilon_{11}^{p}\left(\frac{a^{\prime}}{N}+\frac{b^{\prime}}{N}\right)-\left(\frac{\sigma_{1}^{\prime}}{\sigma_{3}^{\prime}}\right)\left(\frac{1-\sin \phi_{f}^{\prime}}{1+\sin \phi_{f}^{\prime}}\right)\left(\varepsilon_{11}^{p}\left(\frac{a^{\prime}}{N}+\frac{b^{\prime}}{N}\right)\right)+\kappa\left(\frac{d B B I}{d N}\right)\left(\frac{1}{\sigma_{3}^{\prime}}\right)\left(1-\sin \phi_{f}^{\prime}\right)\right]
$$

The values of $d \varepsilon_{v}^{p} / d \varepsilon_{1}^{p}$ can be computed from Equation (21) for a corresponding friction mobilisation, and progressive breakage and stress state evolution during loading or reloading. In this study the FEM simulations were carried out at low values of $N$ (up to $10^{4}$ ) because ballast undergoes minor incremental rates of plastic deformation, implying negligible breakage beyond $10^{4}$ load cycles [45]. 
A sinusoidal cyclic vertical stress $\left(\sigma_{c y c}^{\prime}=402 \mathrm{kPa}\right)$ and lateral stresses $\left(\sigma_{h 2}^{\prime}=10 \mathrm{kPa}\right.$ and $\sigma_{h 3}^{\prime}$ $=7 \mathrm{kPa}$ ) were applied to the triaxial prismoidal specimens. The cyclic stress-strain response of the ballast is shown in Fig. 9a. An elasto-plastic model for track substructure was proposed and discretised in a 2D plane strain FE analysis (Fig. 9b). The Hardening Soil (HS) model was based on an appropriate isotropic hardening plasticity to simulate the strain-hardening behaviour of ballast. More details of this approach are given in Indraratna and Nimbalkar [45]. The sub-ballast and subgrade were both represented with a standard Mohr-Coulomb (MC) model, where the MC model has five key parameters [i.e. Young's modulus $(E)$, Poisson's ratio $(v)$, effective cohesion $(c)$, effective friction angle $(\phi)$, and dilatancy angle $(\psi)]$. The sub-ballast with the following properties: $E=140 \mathrm{MPa}, v=0.35, \psi=5$ and $\phi^{\prime}=35$ degree was included, and subgrade with $E=60 \mathrm{MPa}, v=0.33, c^{\prime}=20$ and $\phi^{\prime}=10$ degree was simulated. The wooden sleeper $\left(E=10 \mathrm{GPa}, v=0.15, \gamma=17 \mathrm{kN} / \mathrm{m}^{3}\right)$ and steel boundary wall $\left(E=210 \mathrm{GPa}, v=0.15, \gamma=77 \mathrm{kN} / \mathrm{m}^{3}\right)$ were considered to be linear elastic. The shockmat $\left(E=6.12 \mathrm{MPa}, v=0.48, \gamma=12.04 \mathrm{kN} / \mathrm{m}^{3}\right)$ was also modelled as a linear elastic material [7], and linear elastic tension elements were used to model the geosynthetic layer. The axial stiffness of the geosynthetic was determined as $E A=F /(\Delta L / L)$, where $F$ is the applied axial force per unit width of the test sample and $\Delta L / L$ is the axial strain. The zerothickness interface elements available in PLAXIS [42] were used to model friction between the various layers, and they were simulated by five-node line elements. The strengths of the interface elements were linked through a strength reduction factor $\left(R_{\text {int }}\right)$ which was assumed to be $1 / 2$ for the soil-geotextile interface and $2 / 3$ for the soil-geogrid interface $[46,47]$.

The results of the experimental tests were compared with the predictions of an FE analysis (Fig. 10a) that indicated that geosynthetics substantially reduced the vertical displacement of ballast. The rapid increase in ballast deformation at the initial stage of cyclic loading and the 
further increase at a reduced rate that eventually attained stabilisation, was captured by FEM. The initial rapid settlement originated primarily from the reorientation of the sharp angular ballast assembly and breakage along the asperities. Moreover, the use of single layer and dual layer geosynthetics helped to reduce deformation. Variations between the lateral displacement and the number of load cycles are plotted in Fig. 10(b), and indicate that the lateral displacements predicted by the current 2D elasto-plastic analysis deviated slightly from the measured data. This is possibly because particle breakage was only assessed at the end of the test. The reduction in lateral displacement due to the use of single and dual geosynthetic layer arrangements reveals how they imparted better lateral stability to the track. The FE model could simulate the relative performance of single and dual layers of geosynthetics placed in the model track and it was in reasonable agreement with the test data.

The reasonable assumption of $2 \mathrm{D}$ plane strain (longitudinal strain $<<$ transverse strain) has been established through results of monitoring of tracks, e.g. Bulli, Sandgate and Singleton. In plane strain analysis, the stress tensor is still $3 \mathrm{D}$, but in the direction of the intermediate stress along the direction of train passage (longitudinal), the strain is assumed to be very small. The movement of ballast particles or strain of ballast layer under the sleeper is essentially a three dimensional problem. However, this is a local phenomenon and does not represent the overall track behavior along a straight stretch containing many sleepers. Although the actual stress-strain states may not be simulated exactly, especially near the boundaries, this numerical track model reasonably simulates realistic track behavior [45]. Although the discrete nature of sleepers and wheel load assembly is of strictly threedimensional, two-dimensional numerical simulation is an appropriate and reasonable idealization on the basis of track measurements.

By assuming 2D plane strain (i.e. zero longitudinal strain in the direction of intermediate stress), errors are introduced to the deformation mode although the stress tensor is in $3 \mathrm{D}$. The 
finite element predictions could certainly be improved by (i) measuring variation of particle breakage against number of load cycles and updating the stress-dilatancy approach at closer time steps, and (ii) implementing a true three dimensional analysis with cyclic loads rather than an assumed 2D Plane Strain model.

\subsubsection{Finite element modelling of ballast degradation induced by impact loading}

During impact loading, two types of distinct force peaks were observed viz. (i) an instantaneous sharp peak $P_{1}$ with a very high frequency, and (ii) a gradual peak with a smaller magnitude $P_{2}$ and with relatively lower frequency (Fig. 11a). The multiple $P_{1}$ peaks were related to impacts, including the first impact from the free fall of a hammer and subsequent blows from a rebounded hammer. The single peak $P_{2}$ was related to the mechanical resistance of the ballast that led to its significant compression. The $P_{2}$ peak was less than the instantaneous $P_{1}$ peaks. The transient $P_{2}$ force load-time histories were digitally filtered by using a low-pass Butterworth filter, and were used as input for the dynamic finite element analysis in PLAXIS [42].

A typical axi-symmetric specimen model was simulated in a finite element discretisation (Fig. 11b) where laterally distributed loads were applied to the right boundary to represent the confining effects of a thick rubber membrane. The left (axis of symmetry) and bottom boundaries were restrained in the lateral and vertical directions, respectively, while the top and right boundaries were free to move. The node at the left bottom corner of the mesh was restrained in the vertical and horizontal directions (pinned support - standard fixity), while the

right and bottom boundaries were considered to be adsorbent boundaries. The MC model was used to simulate a relatively weak subgrade (i.e., poorly graded sand) and the parameters used were $E=45 \mathrm{MPa}, v=0.33, c^{\prime}=0, \phi^{\prime}=24^{0}$ and $\psi=0$. The HS model was used to simulate the strain-hardening behaviour of ballast under impact loading. The large-scale laboratory tests [7] revealed that impact loads caused the most significant damage to ballast, 
and a reduction of about $47 \%$ in particle breakage was possible due to placement of shockmat above and below the ballast layer. The details of the HS material parameters and breakage parameters are given in Table 2. More details of this approach are given by Nimbalkar et al. [7]. The shockmat was also modelled as a linear elastic material, as discussed in the earlier Section. $R_{\text {int }}$ was considered to be $2 / 3[46,47]$, and the steel plates at top and bottom of the test sample were considered to be linear elastic, using same parameters reported in the previous Section.

Figure 12(a) shows the prediction of axial strain by the finite element model using the impact pulse data obtained in the laboratory impact testing. The axial strains were compared with the data measured in the laboratory of ballast with and without the placement of shock mats for hard and weak subgrade conditions. Figure 12(a \& b) shows how the finite element analysis captured the strain hardening behaviour of ballast under repeated impact loads. Both the axial and radial strains increased rapidly during the initial impact blows, a condition that was attenuated further with a larger number of blows. It was interesting to note considerable amount of deformation evident at relatively smaller numbers of load applications compared to cyclic loading, as discussed in the previous section. This was primarily contributed to the transient nature of impact loads with much larger magnitudes. This observation also agreed with field practice where rapid deformation occurred at the dipped welds or joints, turnouts, or on approaches to the decks of bridges where impact loads were exerted. The FE simulation captured the plastic yielding that was influenced by the amount of viscous damping of ballast material. A comparison of the axial and lateral strains predicted by the FE model with the laboratory data revealed that the $P_{1}$ forces had a negligible influence on the ballast. These macromechanical observations obtained from FEM explained the reduced breakage of ballast using shockmats, as measured experimentally. 
While DEM is used to study the micromechanical nature of ballast (i.e. angularity, contact force distribution, etc.), FEM is an essential tool to examine the deformation of ballasted track as a continuum under impact loading. Given the limitation of the current DEM model as mentioned earlier, it is not suitable for simulating the impact loading described here.

\section{CONCLUSIONS}

This paper discussed the results of numerical modelling using the finite element and discrete element methods. A discrete element analysis (PFC2D) was implemented to study the shear behavior of fresh and coal fouled ballast. The shear stress-strain response and volumetric changes were simulated and compared with the experimental results. The micromechanical parameters were obtained to correctly simulate the interaction between geogrid and ballast. DEM simulations were conducted on fresh and fouled ballast at various levels of fouling to study the volumetric change and corresponding stress-strain behaviour of this granular assembly. The DEM simulation indicated that coal fines would reduce the shear strength and increase the dilation of fouled ballast at relatively high levels of VCI.

A two-dimensional finite element analysis (PLAXIS) captured the plane strain response of ballast using an isotropic hardening model in conjunction with a modified stress-dilatancy approach. The results indicated that the $2 \mathrm{D}$ (plane strain) finite element model could predict the stress-strain-degradation of a reinforced and unreinforced model track system with reasonable accuracy. The large-scale laboratory tests revealed that impact loads caused the most significant damage to ballast, and a substantial reduction (about 47\%) in particle breakage was obtained by using shockmats. The results of experimental tests were compared with the FE predictions and indicated that the FE predictions essentially agreed with the laboratory data for two different cases of subgrades. The findings of these numerical studies at the micro- and macro-scale, allows for a better understanding of crucial aspects such as the 
ballast-geogrid interface mechanism, and long-term deformation and degradation, as well as the practical benefits of using geosynthetics and shockmats.

\section{ACKNOWLEDGEMENT}

The authors are grateful to the Australian Research Council, Sydney Trains (formerly, RailCorp), ARTC and Aurizon (formerly, QR National) for their continuous support. A significant portion of the contents have been reproduced with kind permission from the Journal of Geotechnical and Geoenvironmental Engineering ASCE, International Journal of Geomechanics ASCE, Computers and Geotechnics, Geotechnique, and Canadian Geotechnical Journal. 


\section{REFERENCES}

[1] Selig ET, Waters JM. Track Geotechnology and Substructure Management. Thomas Telford, London, UK; 1994.

[2] Li D, Selig ET. Method for railroad track foundation design. I: Development. J Geotech Geoenviron Eng 1998; 124(4): 316-322.

[3] Indraratna B, Nimbalkar S, Coop M, Sloan SW. A constitutive model for coal-fouled ballast capturing the effects of particle degradation. Compu Geotech 2014; 61(9): 96107.

[4] Indraratna B, Sun QD, Nimbalkar S. Observed and predicted behaviour of rail ballast under monotonic loading capturing particle breakage. Can Geotech J 2015; 52(1): 7386.

[5] Jenkins HM, Stephenson JE, Clayton GA, Morland JW, Lyon D. The effect of track and vehicle parameters on wheel/rail vertical dynamic forces. Rail Eng J 1974; 3: 2-16.

[6] Remennikov AM, Kaewunruen S. A review of loading conditions for railway track structures due to train and track vertical interaction. Structural control and Health monitoring 2008; 15(2): 207-234.

[7] Nimbalkar S, Indraratna B, Dash SK, Christie D Improved performance of railway ballast under impact loads using shock mats. J Geotech Geoenviron Eng 2012; 138(3): 281294.

[8] Indraratna B, Ngo NT, Rujikiatkamjorn C. Behavior of geogrid-reinforced ballast under various levels of fouling. Geotext Geomembranes 2011; 29(3): 313-322.

[9] Woodward PK, Kennedy J, Medero GM, Banimahd M. Application of in situ polyurethane geocomposite beams to improve the passive shoulder resistance of railway track. Proc. Inst Mech Engineers, Part F: J Rail and Rapid Transit 2012; 226(3): 294-304. 
[10] Kachi T, Kobayashi M, Seki M, Koseki, J. Reinforcement of railway ballasted track with geosynthetic bags for preventing derailment. Geosyn Intl 2013; 20(5): 316-331.

[11] Indraratna B, Nimbalkar S, Christie D, Rujikiatkamjorn C, Vinod JS. Field assessment of the performance of a ballasted rail track with and without geosynthetics. J Geotech Geoenviron Eng 2010; 136(7): 907-917.

[12] Indraratna B, Nimbalkar S, Neville T. Performance assessment of reinforced ballasted rail track. Ground Improvement 2014; 167(1): 24-34.

[13] Indraratna B, Nimbalkar S, Rujikiatkamjorn C. From Theory to Practice in Track Geomechanics - Australian Perspective for Synthetic Inclusions. Transport Geotech J 2014; 1(4): 171-187.

[14] Indraratna B, Biabani MM, Nimbalkar S. Behavior of geocell-reinforced subballast subjected to cyclic loading in plane-strain condition. J. Geotech. Geoenviron. Eng. 2015; 141(1): 04014081.

[15] Cundall PA, Strack ODL. A discrete numerical model for granular assemblies. Geotechnique 1979; 29(1): 47-65

[16] Lim WL, McDowell GR. Discrete element modelling of railway ballast. Granular Matter 2005; 7(1): 19-29.

[17] Ngo NT, Indraratna B, Rujikiatkamjorn C. DEM simulation of the behavior of geogrid stabilised ballast fouled with coal. Comput Geotech 2014; 55: 224-231.

[18] Tutumluer E, Huang H, Bian X. Geogrid-aggregate interlock mechanism investigated through aggregate imaging based discrete element modeling approach. Int J Geomech 2012; 12(4): 391-398.

[19] Indraratna B, Ngo N, Rujikiatkamjorn C, Vinod J. Behavior of fresh and fouled railway ballast subjected to direct shear testing: Discrete element simulation. Int J Geomech 2014; 14(1): 34-44. 
[20] Chang CS, Adegoke CW, Selig ET. GEOTRACK model for railroad track performance. J Geotech Engg Div ASCE 1980; 106 (11): 1201-1218.

[21] Huang YH, Lin C, Deng X, Rose J. KENTRACK, a computer program for hot-mix asphalt and conventional ballast railway trackbeds. Res. Rep. No. RR-84-1, Asphalt Inst. College park, Md. 1984.

[22] Shahu JT, Kameswara Rao NSV, Yudhbir. Parametric study of resilient response of tracks with a sub-ballast layer. Can Geotech J 1999; 36(6): 1137-1150.

[23] Indraratna B, Nimbalkar S, Rujikiatkamjorn C. Enhancement of rail track performance through utilisation of geosynthetic inclusions, Geotech. Engng. J. of SEAGS \& AGSSEA 2014; 45(1): 17-27.

[24] Nimbalkar S, Indraratna B. Improved performance of ballasted rail track using geosynthetics and rubber shockmat, J. Geotech Geoenviron Eng 2016; doi: 10.1061/(ASCE)GT.1943-5606.0001491 (ahead of print).

[25] Mishra D, Qian Y, Huang H, Tutumluer E. An integrated approach to dynamic analysis of railroad track transitions behavior. Transportation Geotechnics 2014; 1(4): 188-200.

[26] Shahraki M, Warnakulasooriya C, Witt KJ. Numerical study of transition zone between ballasted and ballastless railway track, Transportation Geotechnics 2015; 3(3): 58-67.

[27] Suiker AS, de Borst R. A numerical model for the cyclic deterioration of railway tracks. International Journal for Numerical Methods in Engineering 2003; 57(4): 441-70.

[28] Indraratna B, Nimbalkar S. Implications of ballast breakage on ballasted railway track based on numerical modelling. Proc. 13th International Conference of International Association for Computer Methods and Advances in Computational Mechanics (IACMAG 2011), Melbourne Australia, 2011, 1085-1092.

[29] Nimbalkar S, Indraratna B. Numerical and analytical modeling of particle degradation. Proc. 14th International Conference of International Association for Computer Methods 
and Advances in Computational Mechanics (IACMAG 2014), Oka, Murakami, Uzuoka \& Kimoto (Eds.), Taylor \& Francis Group, London, 2014, 261-266.

[30] Zhang X, Burrow M, Zhou S. An investigation of subgrade differential settlement on the dynamic response of the vehicle-track system. Proceedings of the Institution of Mechanical Engineers, Part F: Journal of Rail and Rapid Transit 2015: doi: 10.1177/0954409715613538 (ahead of print).

[31] Sun QD, Indraratna B, Nimbalkar S. Deformation and degradation mechanisms of railway ballast under high frequency cyclic loading, J. Geotech Geoenviron Eng 2016; doi: 10.1061/(ASCE)GT.1943-5606.0001375, 04015056.

[32] Indraratna B, Lackenby J, Christie D. Effect of confining pressure on the degradation of ballast under cyclic loading. Géotechnique 2005; 55(4): 325-328.

[33] Indraratna B, Tennakoon N, Nimbalkar S, Rujikiatkamjorn C. Behaviour of clay fouled ballast under drained triaxial testing. Géotechnique, 2013; 63(5): 410-419.

[34] Jeffs T, Martin M. Assessment of ballast performance for Queensland Railways. Proceedings of tenth international rail track conference, Brisbane, Queensland, 1994; p. $141-147$.

[35] Indraratna B, Nimbalkar S, Tennakoon N. The behaviour of ballasted track foundations: track drainage and geosynthetic reinforcement. GeoFlorida 2010, ASCE Annual GI Conference, Florida, USA, 2010; p. 2378-2387.

[36] Tennakoon N, Indraratna B, Rujikiatkamjorn C, Nimbalkar S, Neville T. The role of ballast fouling characteristics on the drainage capacity of rail substructure. ASTM Geotechnical Testing Journal; 2012; 35(4): 1-12.

[37] Oda M, Iwashita K. Mechanics of granular materials: an introduction. Rotterdam: A. A. Balkema; 1999. 
[38] Itasca. Particle flow code in three dimensions (PFC3D). Itasca Consulting Group, Inc., Minnesota; 2008

[39] Lackenby J, Indraratna B, McDowel GR, Christie D. Effect of confining pressure on ballast degradation and deformation under cyclic triaxial loading. Géotechnique 2007; 57(6): 527-536.

[40] Indraratna B, Ngo N, Rujikiatkamjorn C. Deformation of Coal Fouled Ballast Stabilized with Geogrid under Cyclic Load. J Geotech Geoenviron Eng 2013; 139(8): 1275-1289.

[41] Indraratna B, Thakur PK, Vinod JS. Experimental and numerical study of railway ballast behavior under cyclic loading. Int J Geomech 2010; 10(4): 136-144.

[42] PLAXIS BV. PLAXIS 2D Version 8.6 - Finite element code for soil and rock analysis. Delft, The Netherlands; 2006.

[43] Ueng TS, Chen TJ. Energy aspects of particle breakage in drained shear of sands. Geotechnique 2000; 50(1): 65-72.

[44] Rowe PW. The stress-dilatancy relation for the static equilibrium of an assembly of particles in contact. Proc. Royal Society, 1962; A269: 500-527.

[45] Indraratna B, Nimbalkar S. Stress-strain degradation response of railway ballast stabilized with geosynthetics. J Geotech Geoenviron Eng 2013; 139(5): 684-700.

[46] Brown SF, Kwan J, Thom NH. Identifying the key parameters that influence geogrid reinforcement of railway ballast. Geotextiles and Geomembranes 2007; 25(6): 326-335.

[47] Yegian M, Lahlaf A. Dynamic interface shear strength properties of geomembranes and geotextiles. J Geotech Eng 1992; 118(5): 760-779. 


\section{LIST OF TABLES}

Table 1. Micromechanical parameters adopted for ballast, coal fines and boundary walls in DEM.

Table 2. Macromechanical parameters adopted for ballast in FEM (data sourced from Nimbalkar et al. [7], Indraratna and Nimbalkar [45]). 
Table 1. Micromechanical parameters adopted for ballast, coal fines and boundary walls in DEM.

\begin{tabular}{|l|l|}
\hline Micromechanical parameters & Values \\
\hline Contact normal stiffness of ballast, $k_{n \text {-ballast }}(\mathrm{N} / \mathrm{m})$ & $0.52 \times 10^{8}$ \\
Inter-particle coefficient of friction of ballast, $\mu_{\text {ballast }}$ & $0.52 \times 10^{8}$ \\
Contact normal stiffness of wall-particle, $k_{n-\text { wall }}(\mathrm{N} / \mathrm{m})$ & $1 \times 10^{8}$ \\
Shear stiffness of wall of wall-particle, $k_{s-\text { wall }}(\mathrm{N} / \mathrm{m})$ & $1 \times 10^{8}$ \\
Particle density for ballast $\left(\mathrm{kg} / \mathrm{m}^{3}\right)$ & 2700 \\
Particle density for coal fines $\left(\mathrm{kg} / \mathrm{m}^{3}\right)$ & 1280 \\
Contact normal stiffness of coal fines, $\mathrm{k}_{\mathrm{n} \text {-coal }}(\mathrm{N} / \mathrm{m})$ & $1.27 \times 10^{4}$ \\
Inter-particle coefficient of friction of coal fines, $\mu_{\text {coal }}$ & 0.2 \\
\hline
\end{tabular}


Table 2. Macromechanical parameters adopted for ballast in FEM (data sourced from Nimbalkar et al. [7], Indraratna and Nimbalkar [45]).

\begin{tabular}{|c|c|c|}
\hline Macromechanical Parameter & \multicolumn{2}{|c|}{ Values } \\
\hline Type of loading & Cyclic & Impact \\
\hline Friction angle, $\phi^{\prime}$ (degree) & 64.4 & 74.4 \\
\hline Dilation angle, $\psi$ (degree) & 15.4 & 17.5 \\
\hline Confining pressure, $\sigma_{3}^{\prime}(\mathrm{kPa})$ & & 10 \\
\hline Secant modulus for primary stress path, $E_{50}{ }^{r e f}(\mathrm{MPa})$ & 298.4 & 12.9 \\
\hline $\begin{array}{l}\text { Tangent modulus for primary oedometer stress path, } \\
E_{\text {oed }}^{\text {ref }}(\mathrm{MPa})\end{array}$ & 298.4 & 12.9 \\
\hline $\begin{array}{l}\text { Stiffness modulus for unloading-reloading stress path, } \\
E_{u r}^{r e f}(\mathrm{MPa})\end{array}$ & 895.2 & 12.4 \\
\hline Rate of change of BBI at failure, $\left(d B B I / d \varepsilon_{I}^{p}\right)_{f}$ & 1.5 & 0.7 \\
\hline Empirical coefficient, $\kappa$ (non-dimensional) & 743.8 & 737.5 \\
\hline
\end{tabular}

Note: Average values are reported 


\section{LIST OF FIGURES}

Fig. 1. Mass-volume relationship for fouled ballast (modified after Indraratna et al. [3]).

Fig. 2. Correlation between fouling indices and VCI for various percentages of coal fouling.

Fig. 3. Particle shapes used in the DEM simulations for ballast.

Fig. 4. DEM models for large-scale direct shear test of ballast: (a) Fresh ballast; (b) Fouled ballast $(V C I=40 \%)$.

Fig. 5. Comparisons of shear stress-strain and volumetric response of ballast between experiment and DEM simulation: (a) Fresh ballast; (b) 40\%VCI-fouled ballast (modified after Indraratna et al. [40]).

Fig. 6. DEM analysis for of ballast in Cubical test: (a) Particle shapes; (b) DEM model.

Fig. 7. Comparisons of lateral displacement, settlement and broken bonds between DEM simulations and data measured experimentally (modified after Indraratna et al. [40]).

Fig. 8. Contact force distributions of ballast: (a) Fresh ballast; (b) $70 \%$ VCI-fouled ballast (modified after Indraratna et al. [40]).

Fig. 9. (a) Cyclic stress-strain response; (b) Finite-element mesh discretization of Process Simulation triaxial chamber (data sourced from Indraratna and Nimbalkar [45]).

Fig. 10. Variation of (a) vertical displacement $\left(S_{v}\right)$ and (b) lateral displacement $\left(S_{h}\right)$ for increasing number of cycles: Comparison of FE predictions with test results (data sourced from Indraratna and Nimbalkar [45]).

Fig. 11. (a) Typical transient force response observed during impact blow (b) Finite Element Mesh for the typical test specimen (data sourced from Nimbalkar et al. [7]).

Fig. 12. Variation of (a) vertical strain $\left(\varepsilon_{a}\right)$ and (b) radial strain $\left(\varepsilon_{r}\right)$ for increasing number of cycles: Measured vs FE predicted values (data sourced from Nimbalkar et al. [7]). 

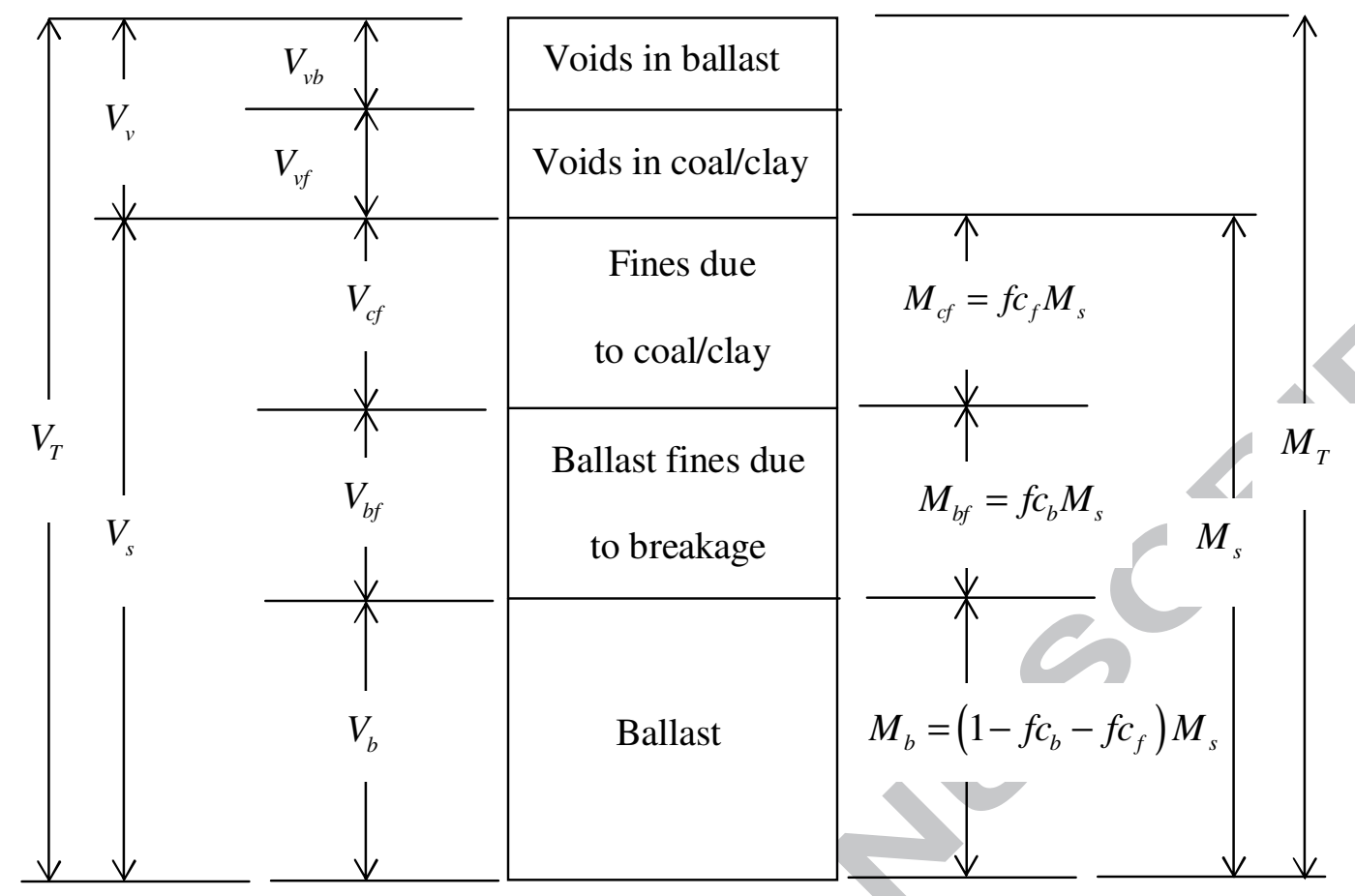

to breakage

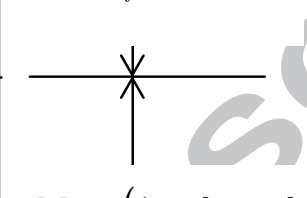

$M_{s}$

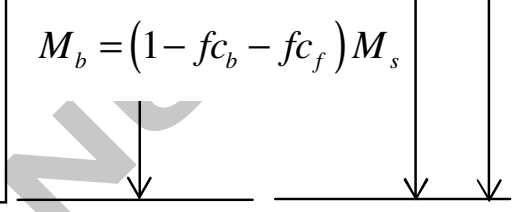

Fig. 1. Mass-volume relationship for fouled ballast (modified after Indraratna et al. [3]). 


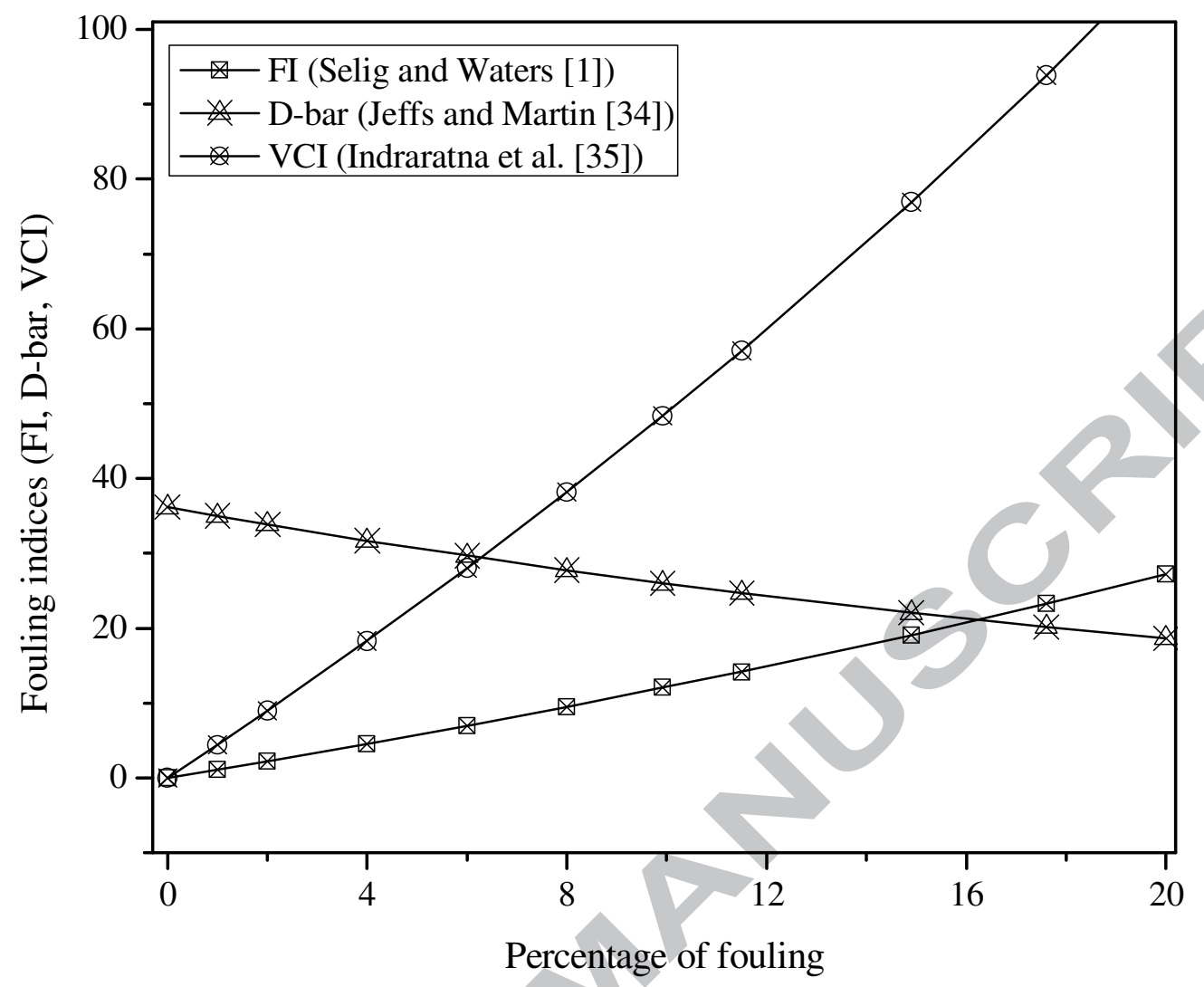

Fig. 2. Correlation between fouling indices and VCI for various percentages of coal fouling. 


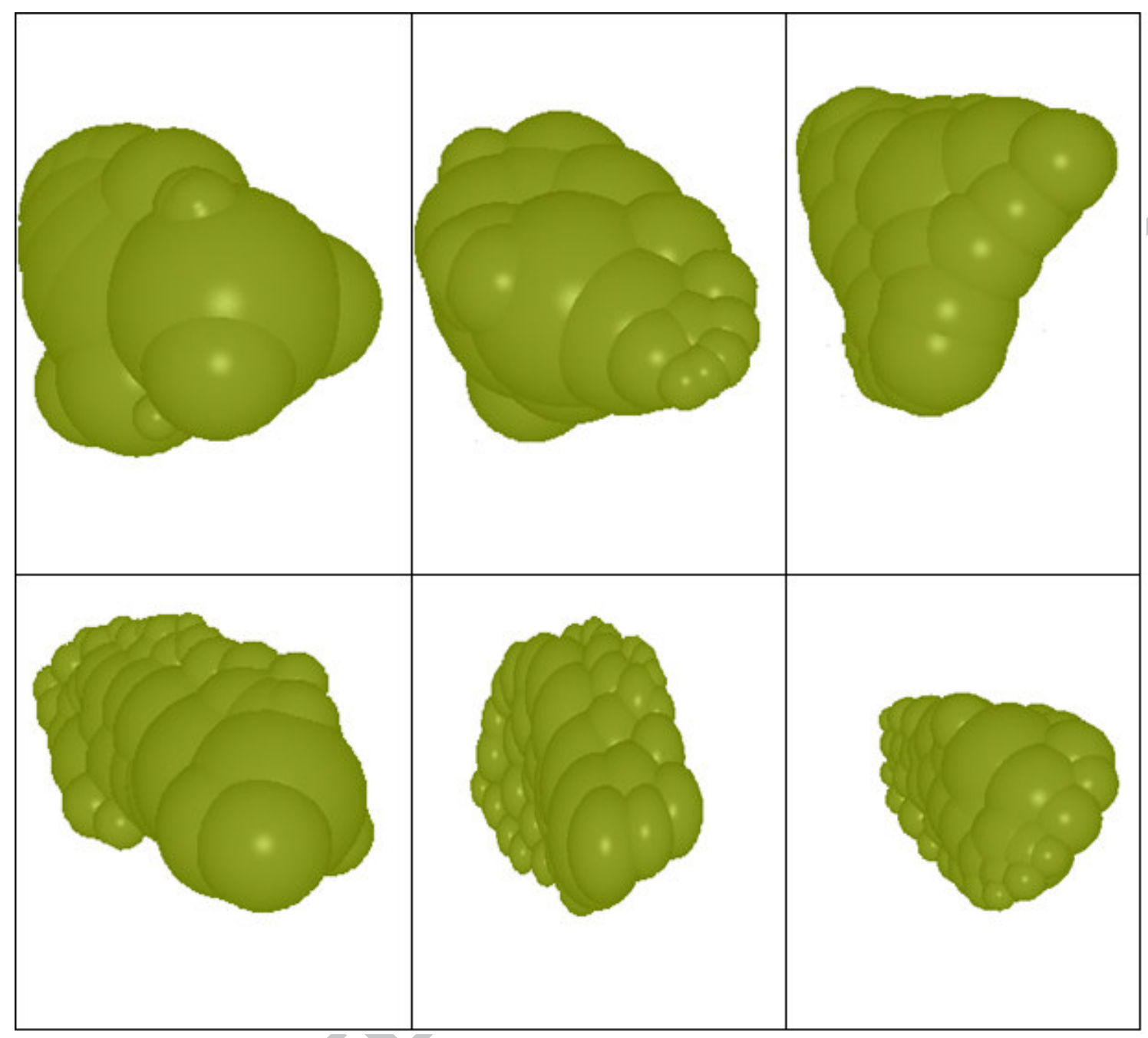

Fig. 3. Particle shapes used in the DEM simulations for ballast 


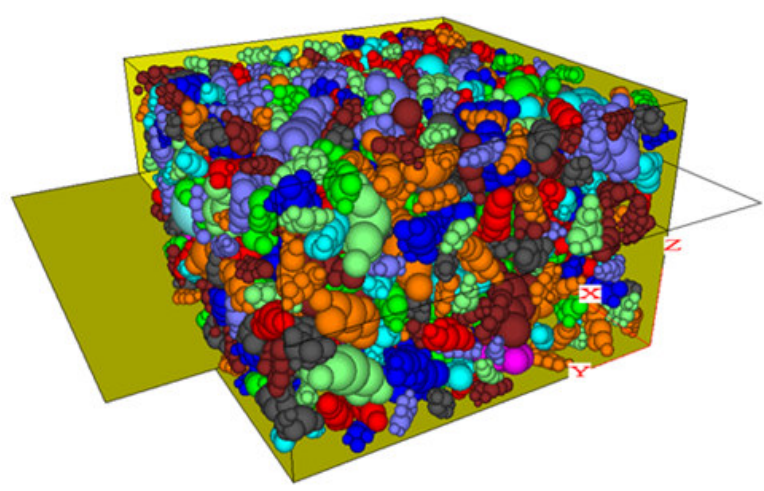

(a)

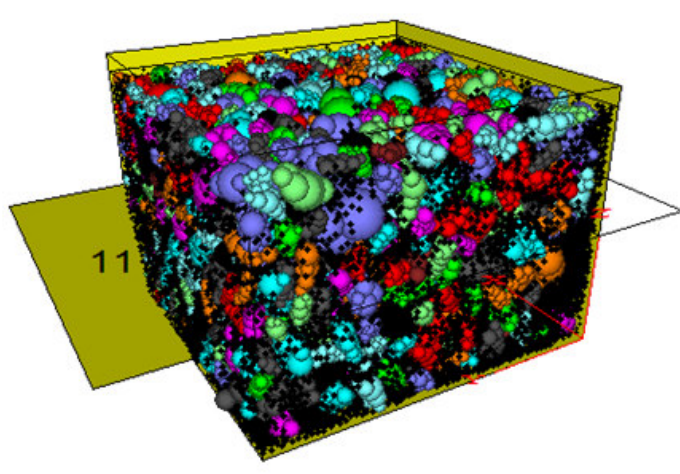

(b)

Fig. 4. DEM models for large-scale direct shear test of ballast: (a) Fresh ballast; (b) Fouled ballast $(V C I=40 \%)$ 


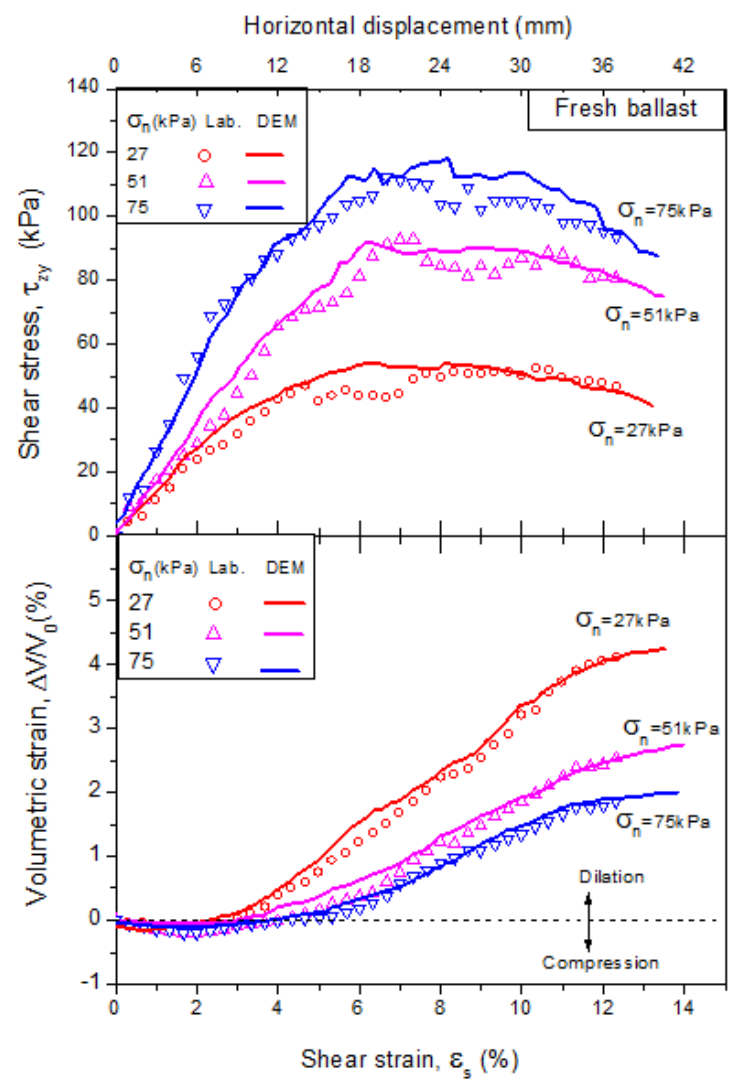

(a)

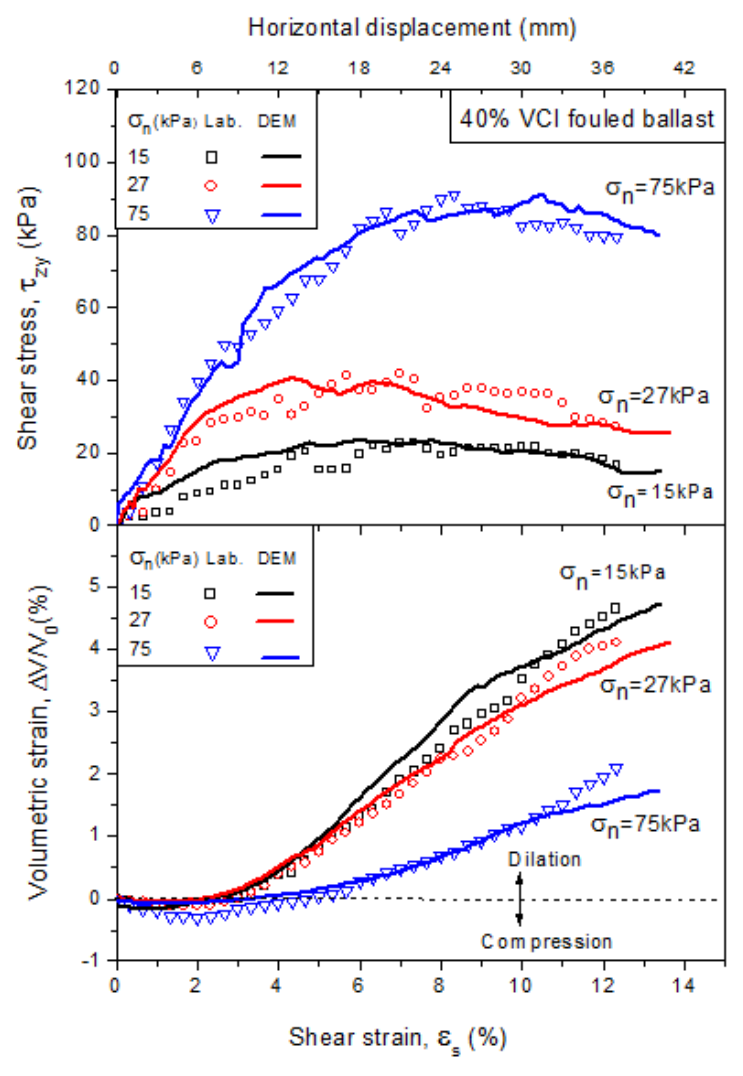

(b)

Fig. 5. Comparisons of shear stress-strain and volumetric response of ballast between experiment and DEM simulation: (a) Fresh ballast; (b) 40\%VCI-fouled ballast (modified after Indraratna et al. [40]). 


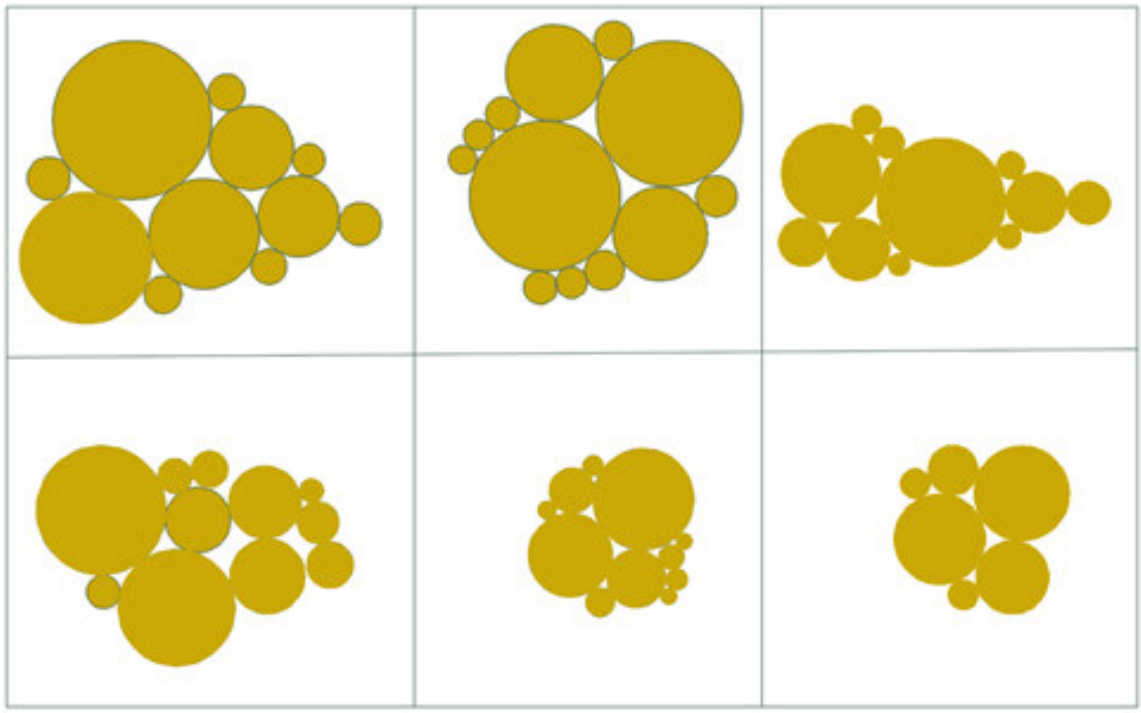

(a)

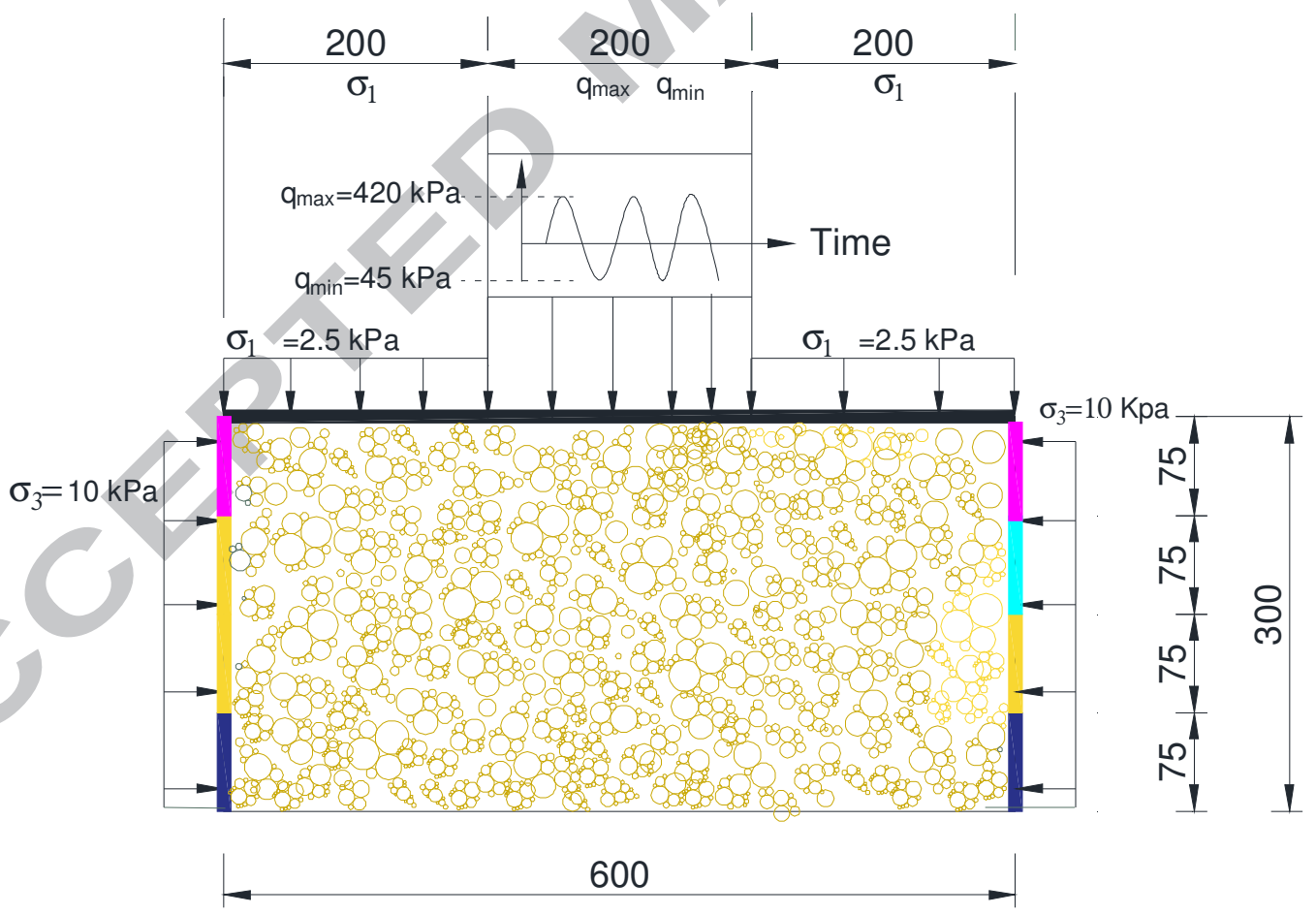

(b)

Fig. 6. DEM analysis for of ballast in Cubical test: (a) Particle shapes; (b) DEM model. 


\section{ACCEPTED MANUSCRIPT}

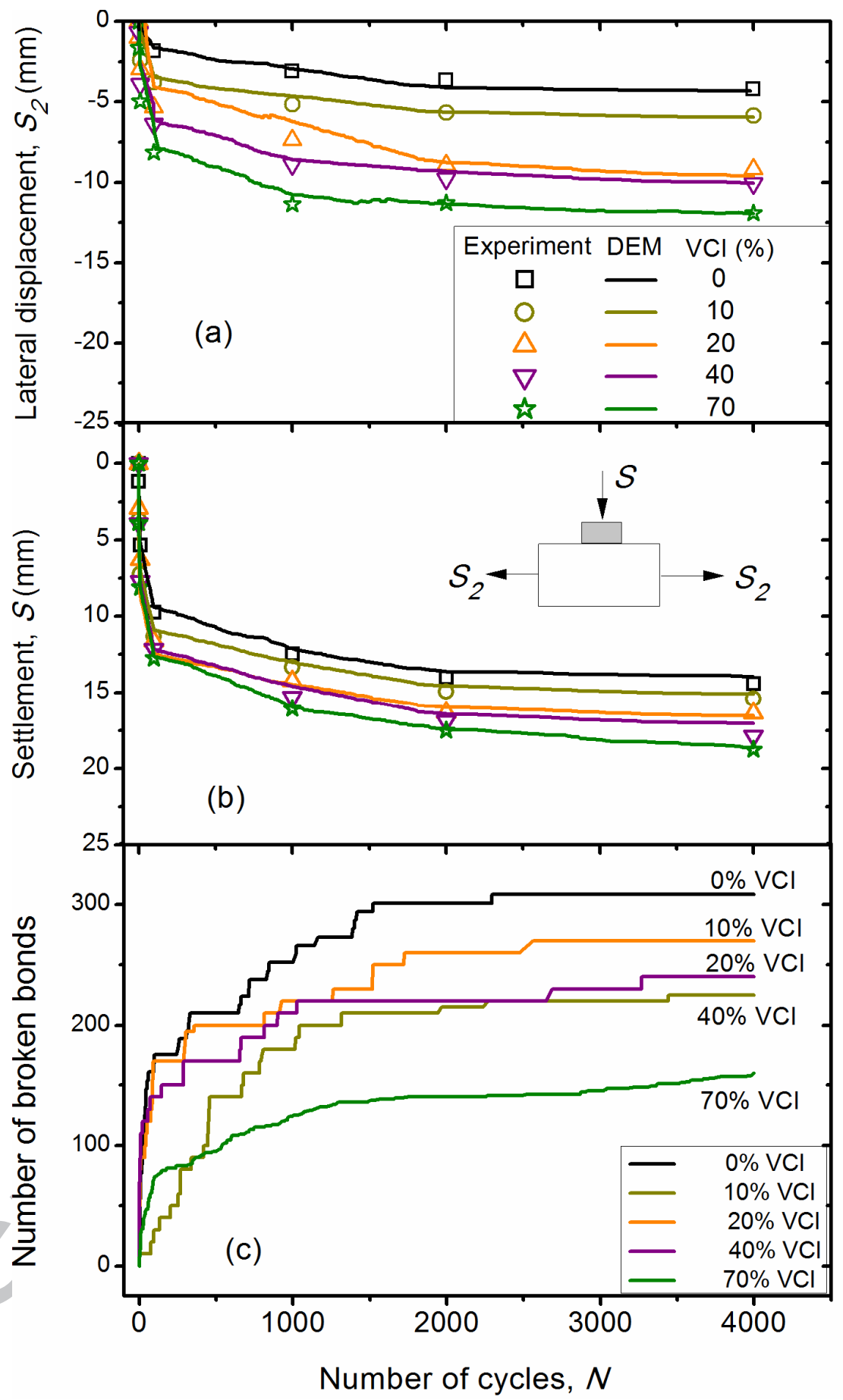

Fig. 7. Comparisons of lateral displacement, settlement and broken bonds between DEM simulations and data measured experimentally (modified after Indraratna et al. [40]). 


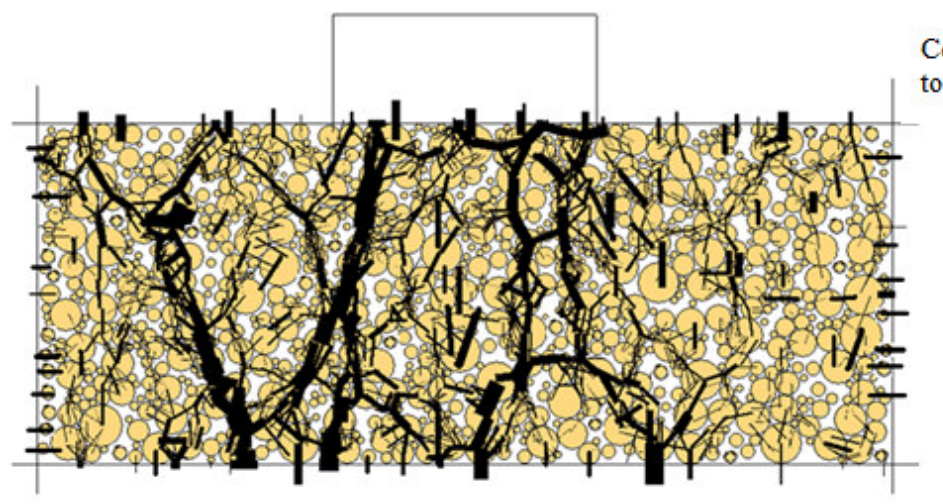

(a) Fresh ballast

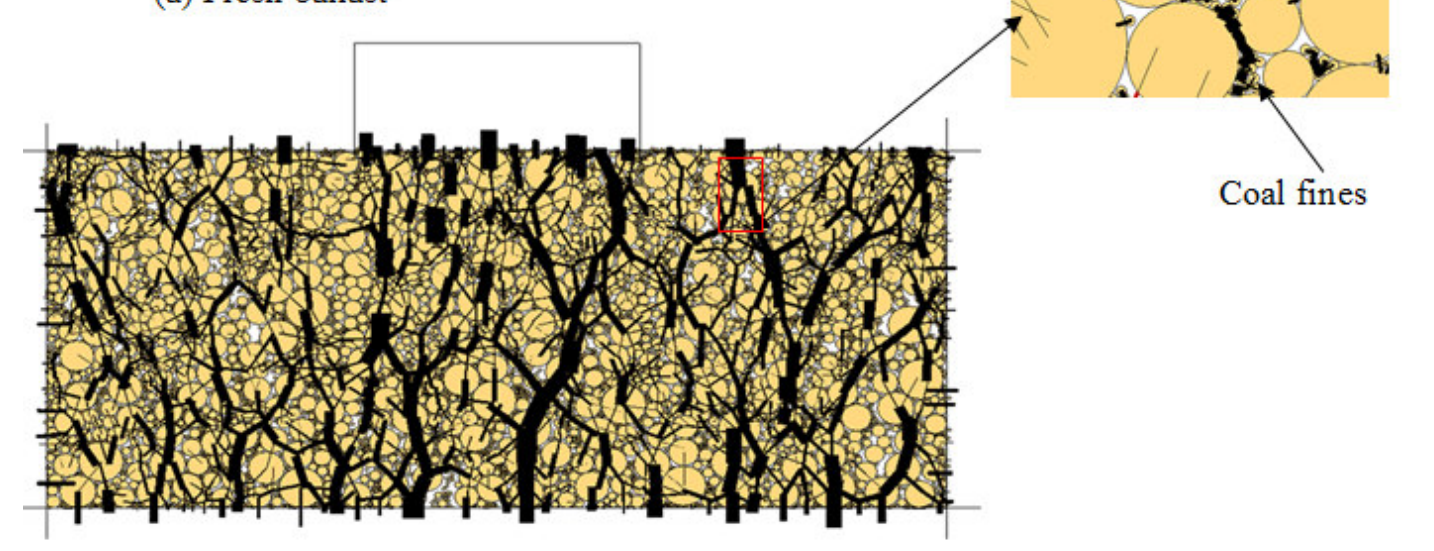

(b) Fouled ballast ( $\mathrm{VCI}=70 \%)$

Fig. 8. Contact force distributions of ballast: (a) Fresh ballast; (b) 70\%VCI-fouled ballast (modified after Indraratna et al. [40]). 


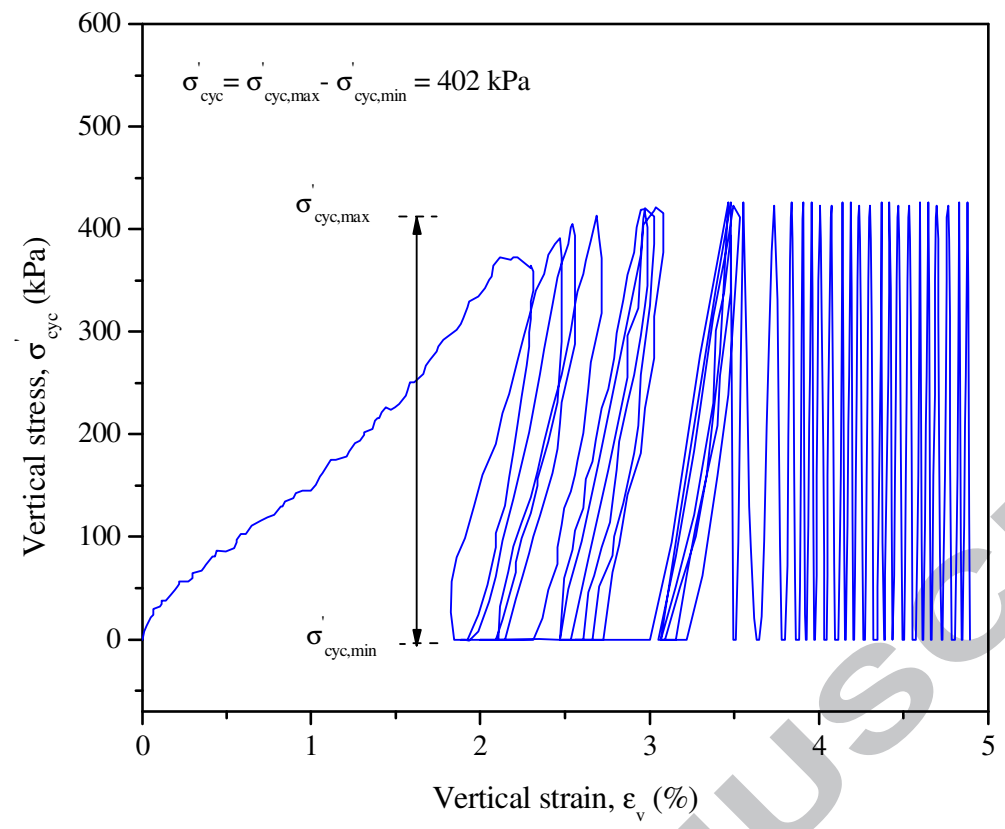

(a)

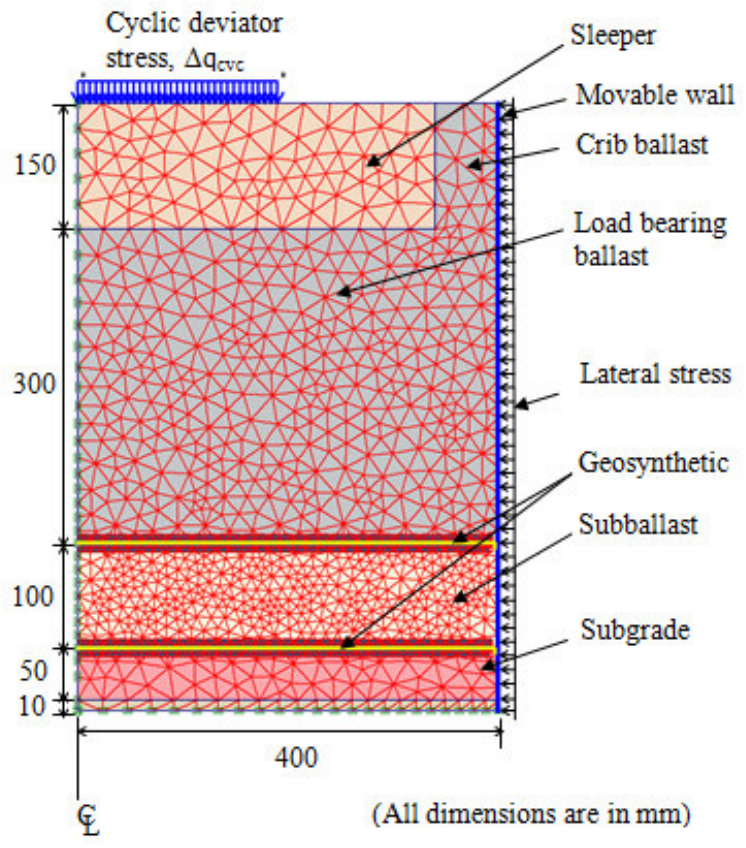

(b)

Fig. 9. (a) Cyclic stress-strain response; (b) Finite-element mesh discretization of Process Simulation triaxial chamber (data sourced from Indraratna and Nimbalkar [45]). 


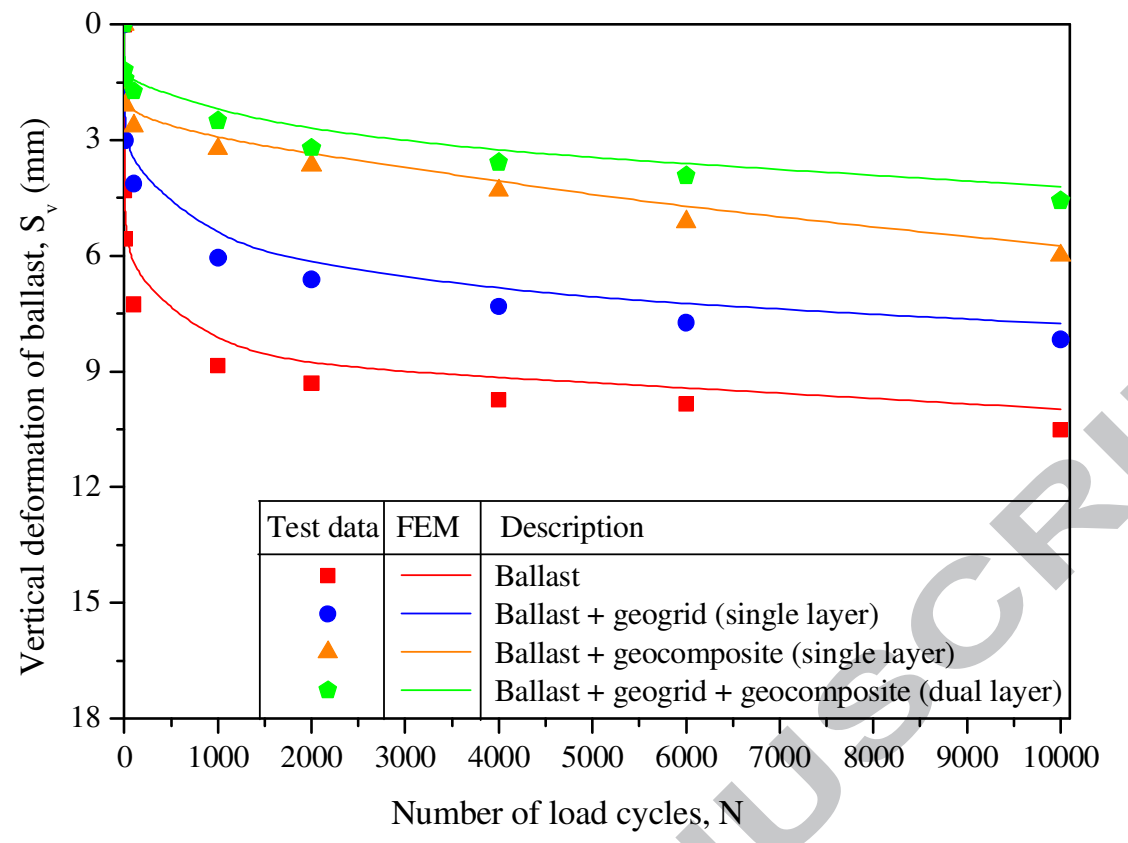

(a)

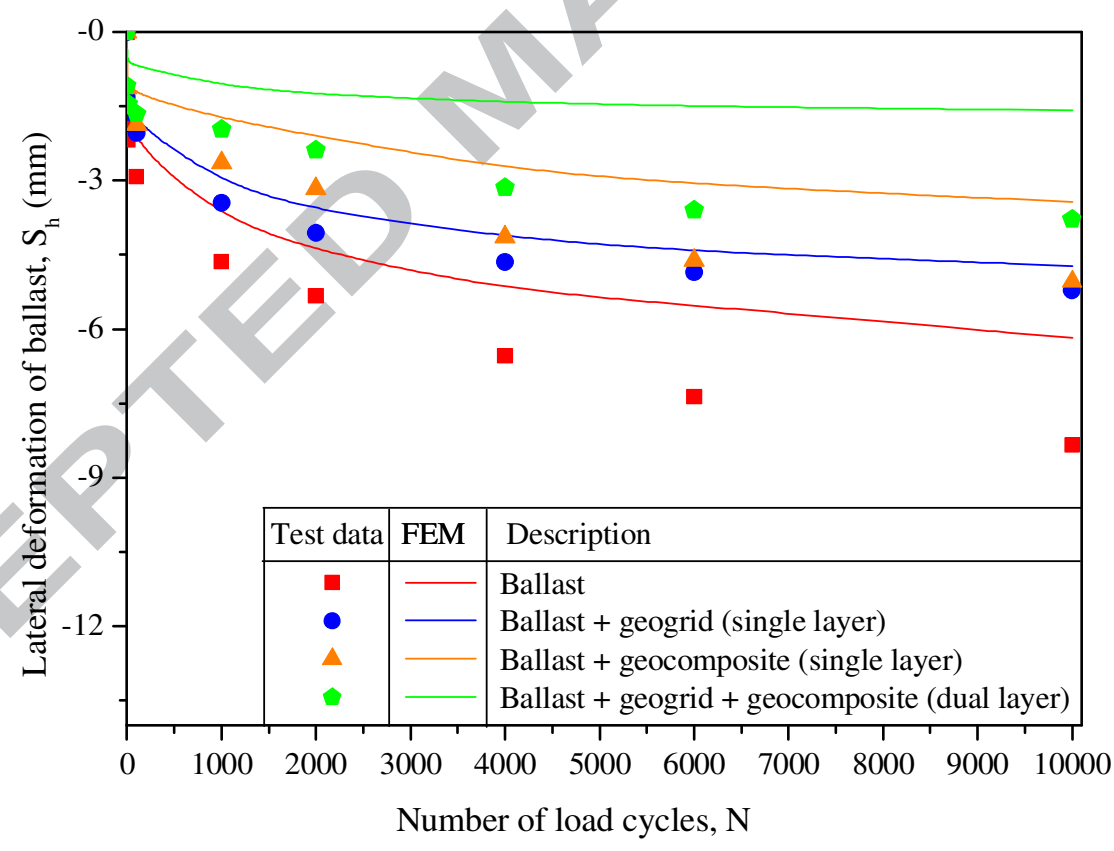

(b)

Fig. 10. Variation of (a) vertical displacement $\left(S_{v}\right)$ and (b) lateral displacement $\left(S_{h}\right)$ for increasing number of cycles: Comparison of FE predictions with test results (data sourced from Indraratna and Nimbalkar [45]). 


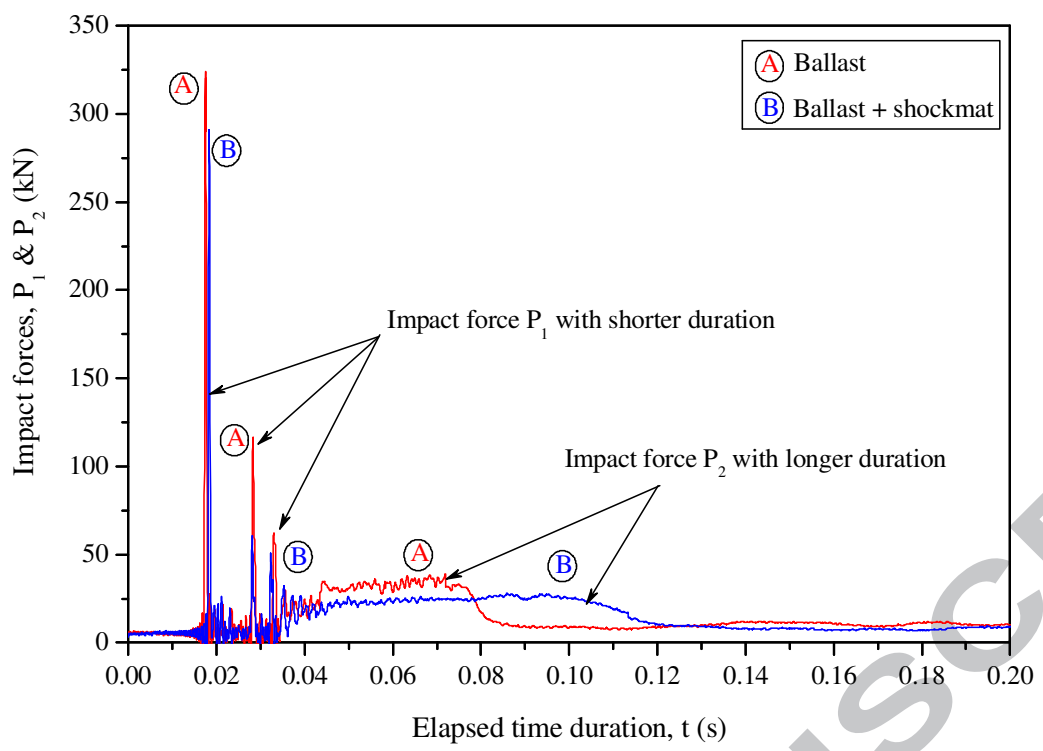

(a)

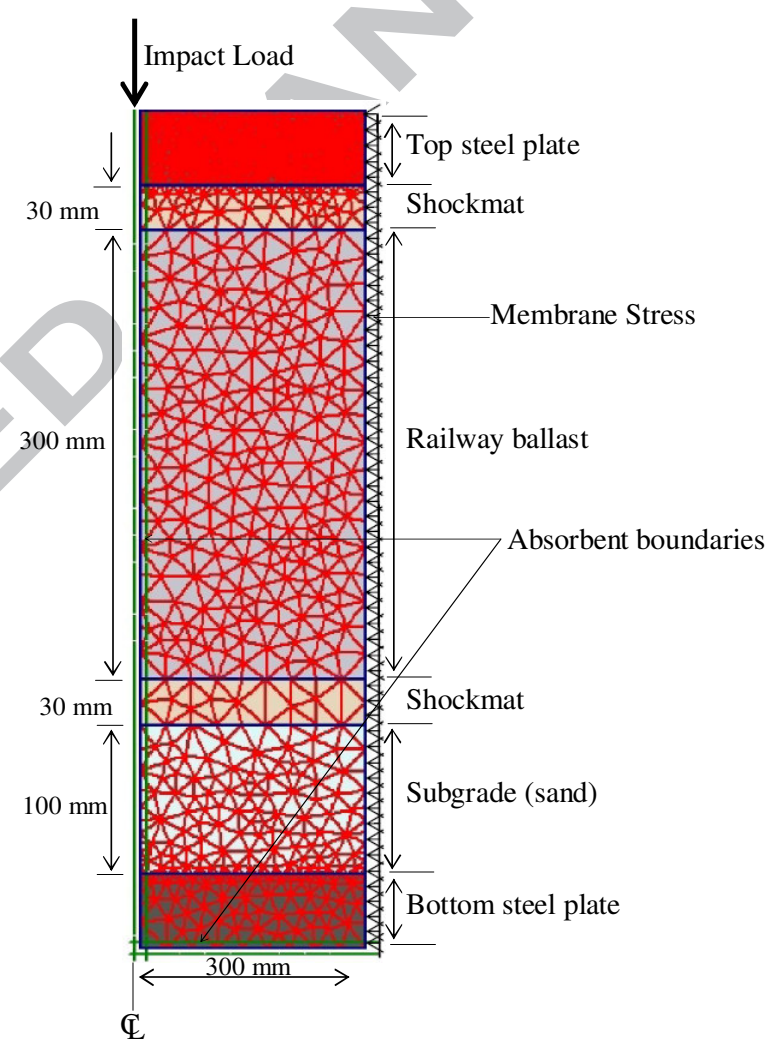

(b)

Fig. 11. (a) Typical transient force response observed during impact blow (b) Finite Element Mesh for the typical test specimen (data sourced from Nimbalkar et al. [7]). 


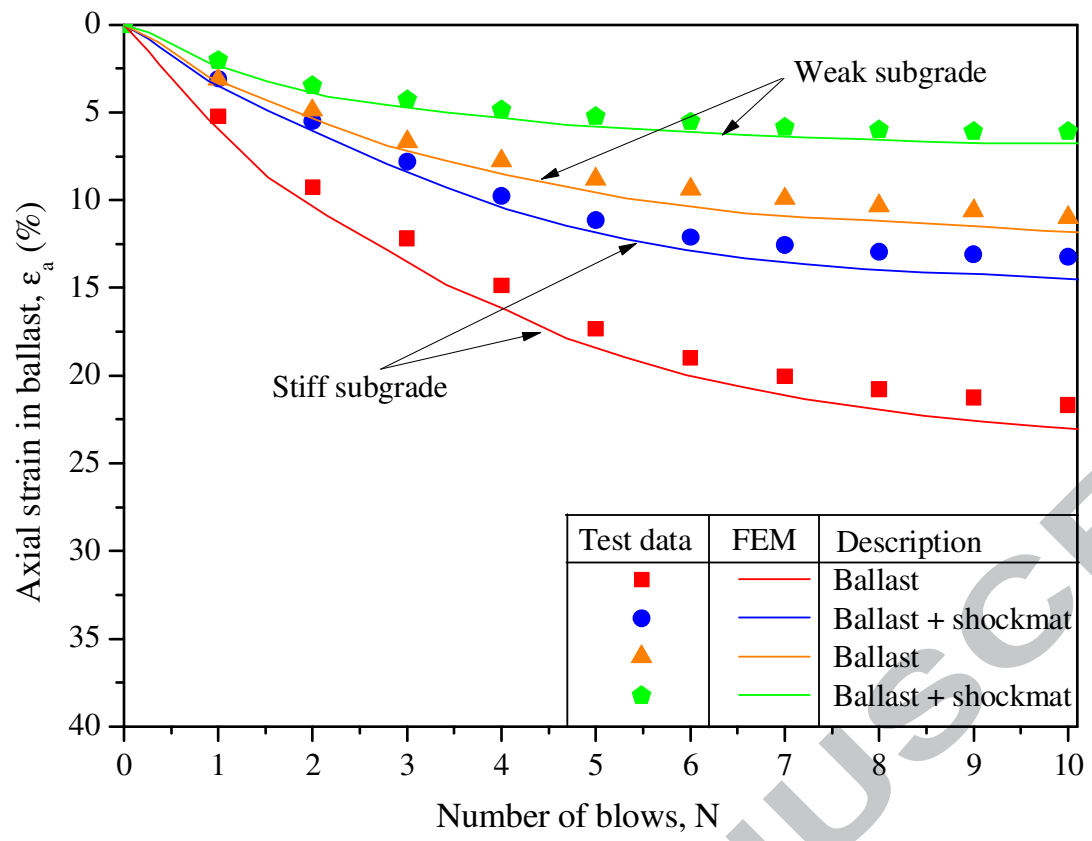

(a)

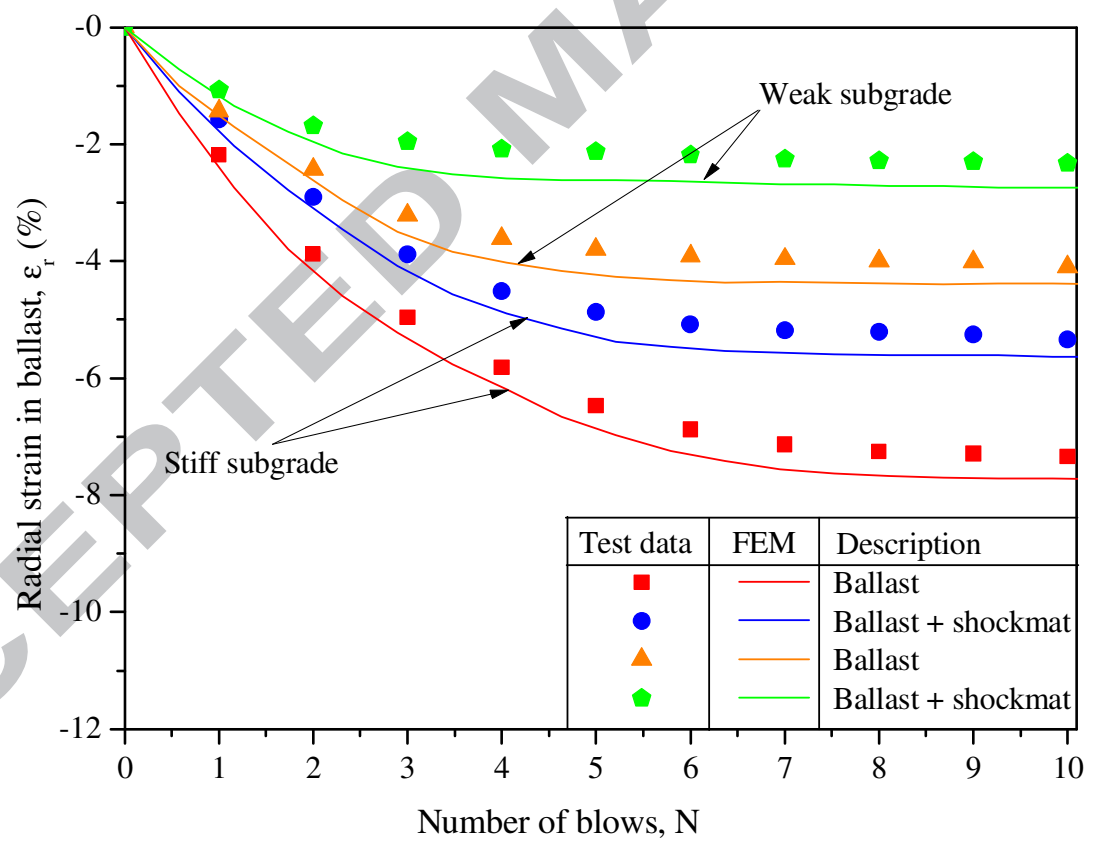

(b)

Fig. 12. Variation of (a) vertical strain $\left(\varepsilon_{a}\right)$ and (b) radial strain $\left(\varepsilon_{r}\right)$ for increasing number of cycles: Measured vs FE predicted values (data sourced from Nimbalkar et al. [7]). 